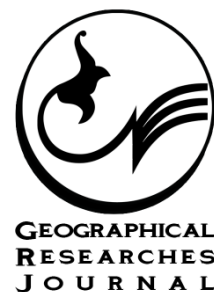

\title{
Importance of Using Modern Irrigation Methods in Increase of Employment and Development of Rural Areas
}

\section{ART I C L E I N F O}

\section{Article Type}

Original Research

\section{Authors}

Moravej k. $*$ PhD

Delavar M.A ${ }^{1} P h D$

Najafi $V^{2} M S c$

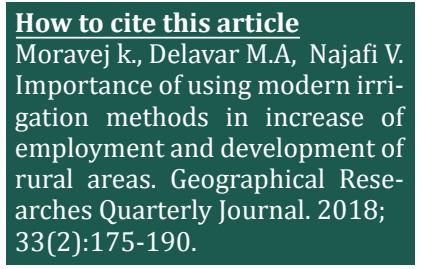

*Department of soil science, Faculty of agriculture, University of Zanjan, Zanjan, Iran

${ }^{1}$ Department of soil science, Faculty of agriculture, University of Zanjan, Zanjan, Iran

${ }^{2}$ Department of soil science, Faculty of agriculture, University of Zanjan, Zanjan, Iran

\section{*Correspondence}

Address: Department of soil science, Faculty of agriculture, Univer-sity of Zanjan, Zanjan, Iran

Phone: -

Fax: -

kmoravej@znu.ac.ir

\section{Article History}

Received: December 20, 2018

Accepted: March 12, 2018

ePublished: September 17, 2018

\begin{abstract}
A B S T R A C T
Introduction and Background Recent droughts have more than ever raised the use of modern irrigation methods and cultivating land having restrictions. This is especially important in rural areas.

Aims This research was conducted for studying the effect of new irrigation methods to increase the area under cultivation with saline and alkaline soils limitation for pistachio land utilization type in part of the south of Tehran province.

Methodology Field studies were conducted such as drilling of 10 soil profiles, 10 augers and 86 soil sampling. various thematic maps such as soil map, land classification and suitability were prepared for two irrigation method as surface (traditional) and localized (modern) using auxiliaries' data such as satellite imagery, geological and topographic maps and weather information and laboratory analysis result from soil sampling. The soils of region were classified at typic torrifluvents sub-group and differentiated at three series and six phases. Land classification study was conducted for bubbler and furrow irrigation method. Land suitability evaluation was handled according to selected irrigation method using parametric corrected land index method for pistachio land utilization type.

Conclusion The results showed the use of bubbler irrigation rather than one may lead to the promotion land classification classes (II S to I) or reduce limitations on a class (II STW to II W). The use of mentioned irrigation method enhances land suitability classes due to insensitivity to soil and land limitations such as topography and salinity (increased from $\mathrm{N}$ to $\mathrm{S} 2 \mathrm{n}$ ) or will reduce the number and severity of limitations. However, the change of irrigation method from traditional to modern needs high costs and demand greater levels of initial management, but in the long term, while increasing irrigation efficiency compensate the preliminary costs and reduce land modifying operations.
\end{abstract}

Keywords Bubbler irrigation; Land classification; Saline soils; Soil map

\section{I T A T I O N L I N K S}

[Ahmadi \& Barzgari; 2012] Economic study of bubbler irrigation in ...; [Albaji, et al; 2008] Land suitability evaluation for surface ...; [Albaji, et al; 2010] Comparison of different irrigation methods ...; [Alipour, et al; 2012] Determination of salinity ...; [Alsaqaf; 2015] Determination of friction ...; [Anonymous; 2014] World reference base for ...; [Askari, et al; 2011] Evaluation of geometric properties of two ...; [Beede, et al; 2005] Diagnosing and correcting nutrient ...; [Beyki, et al; 2017] Study of employment status in ...; [Bouyoucos; 1962] Hydrometer method improved ...; [Burt; 2004] Soil survey laboratory ...; [Darvishzadeh; 1991] Iran geology ...; [Darwish, et al; 2005] Salinity evolution and crop response to ...; [Ebrahimi; 2006] Performance Evaluation of Pressure ...; [Eduful \& Shively; 2015] Perceptions of urban land use and ...; [El-Gindy, et al; 2016] Influence of using different water ...; [FAO; 1998] Soil Map of the ...; [Farshad, et al; 2015] Application of geomorphology, ...; [Farshi, et al; 1997] Estimation of water requirements ...; [Ghaemian \& Najari; 2013] Evaluation of the suitability of pistachio ...; [Jafarzadeh \& Abbasi; 2006] Qualitative land suitability evaluation for the growth of ...; [Jalalian; 2013] The analysis of the impacts of new irrigation ...; [Khalifa \& Ali; 2015] Water productivity, yield and quality of foster grapefruit ...; [Khidir; 1986] A statistical approach in the use of ...; [Mahajan \& Tuteja; 2005] Cold, salinity and drought ...; [Mansour, et al; 2015] Impact of bubbler discharge and irrigation ...; [Moravej; 2017] Classification and land suitability ...; [Nelson; 1982] Carbonate and gypsum. Methods of ...; [Ojidi, et al; 2011] Statistical zoning of land suitability ...; [Onder, et al; 2005] Different irrigation methods and water stress; [Phocaides; 2007] Handbook on pressurized irrigation ...; [Rabia, et al; 2013] Land suitability analysis for ...; [Rhoades, et al; 1996] Salinity: Electrical conductivity and yotal ...; [Salem; 2018] Investigation of factors affecting the ...; [Seyyedjalali, et al; 2014] Comparison of land improvement ...; [Soil Research Institute; 1989] Land use classification guide for ...; [Soil Survey Staff; 2014] Keys to Soil ...; [Soothar, et al; 2015] Comparison of bubbler and basin ...; [Sys, et al; 1991] Land evaluation, part I: Methods in ...; [Traylor \& Zlotnik; 2016] Analytical modeling of irrigation ...; [Van Wambeke; 2000] The newhall simulation model ...; [Waller \& Yitayew; 2016] Lowhead gravity bubbler ...; [Zaynaldin, et al; 2013] An investigation of genesis ... 


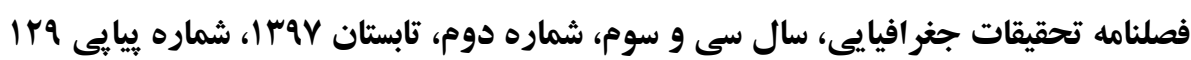

Moravej K. PhD

Delavar M.A. PhD

Najafi V. MA

kmoravej@znu.ac.ir

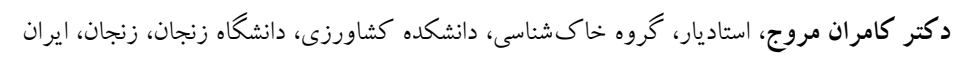

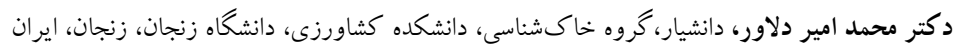

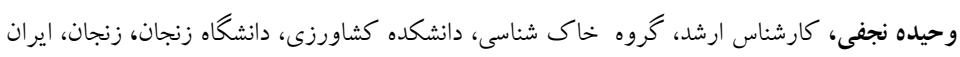

\section{اهميت استفاده از روشهاى نوين آبيارى در افزايش اشتغالزايى و توسعه مناطق روستايى}

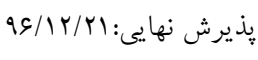

DOI: $10.29252 /$ geores.33.2.175

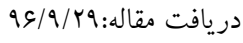

مقدمه: خشكسالىهاى اخير لزوم استفاده ار روشهاى نوين آبيارى و به زير كشت بردن اراضى داراى محدوديت را بيش از

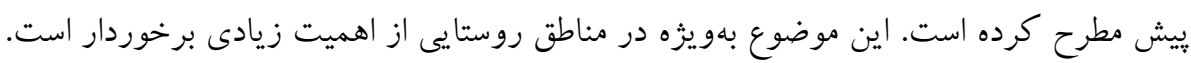

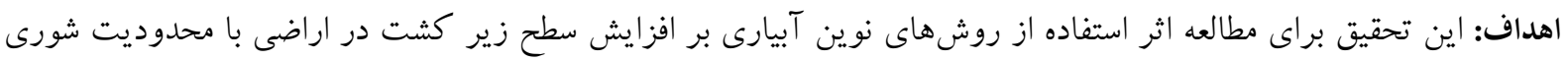

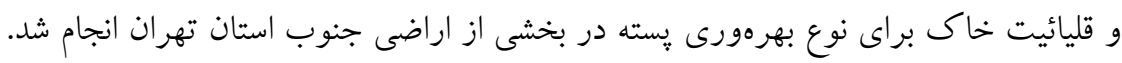

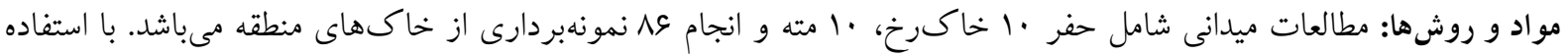

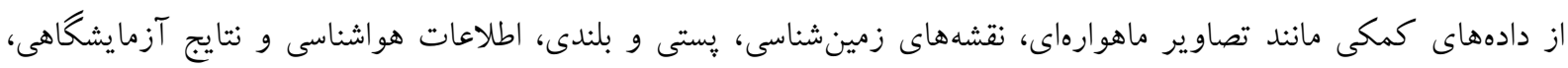

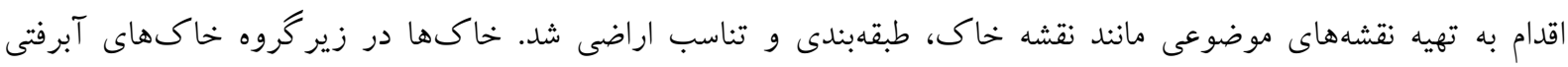
مناطق خشك طبقهبندى و در غالب سه سرى و شش حالت سرى خاك تفكيك شدند. مطالعات طبقهبندى اراضى منطقه براى

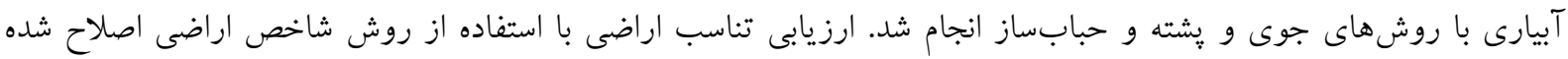

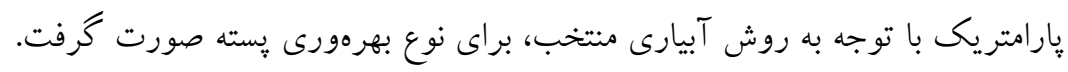

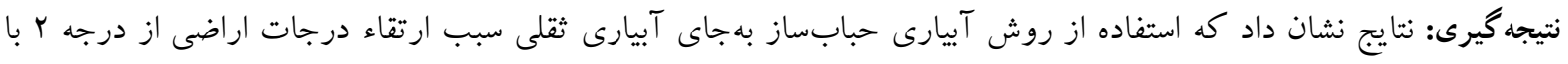

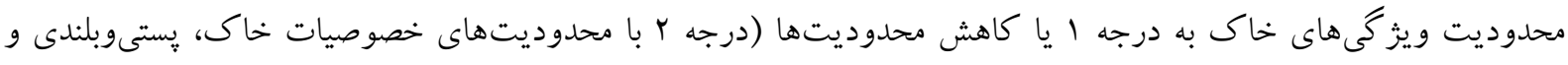

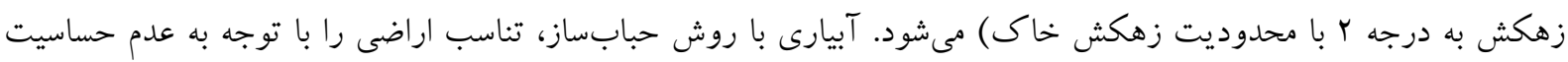

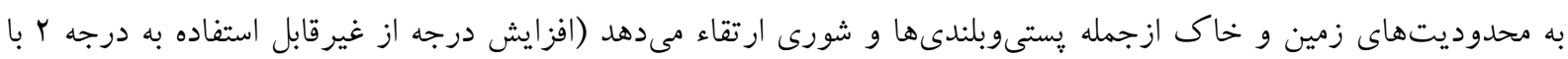

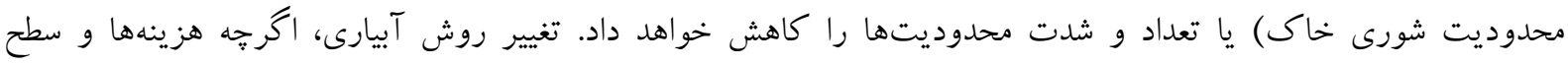

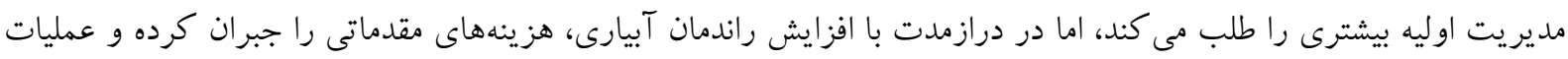

$$
\text { اصلاح اراضى را كاهش مىدهد. }
$$

وازگان كليدى: آبيارى حبابساز، طبقبندى اراضى، خاكهاى شور، نقشه خاك

محدوديت منابع آب همراه با رشد روزافزون جمعيت و مصرف محصولات كشاورزى، ضرورت توجه هرجه بيشتر به

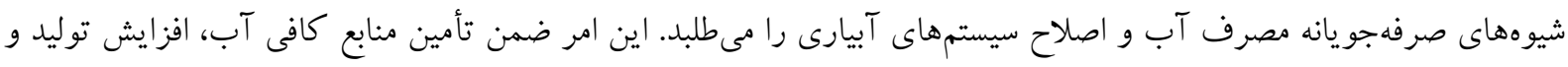


كمك به اقتصاد كشور را در بى خواهد داشت. با توجه به اينكه كشاورزى اصلىترين بخش اقتصاد نواحى روستايى است،

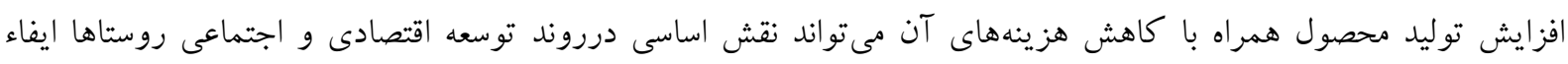

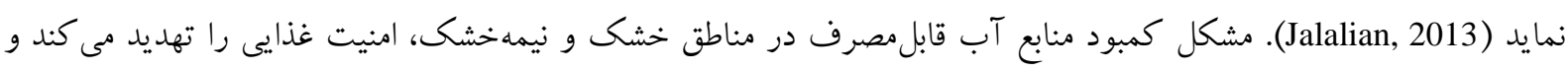

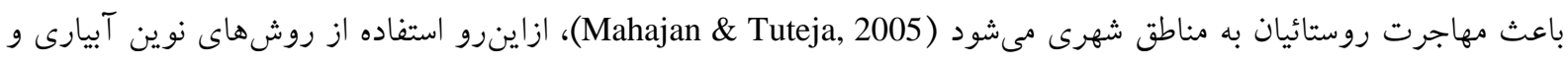

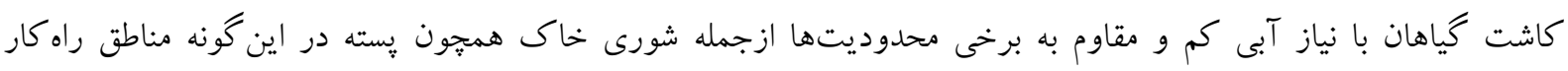

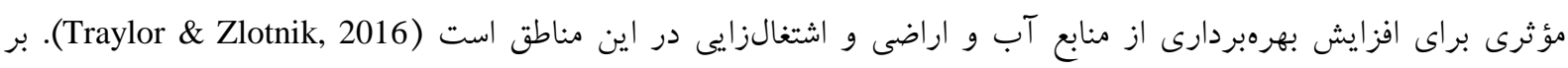

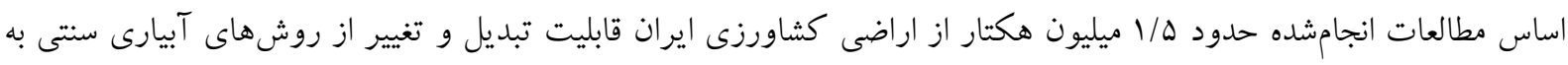

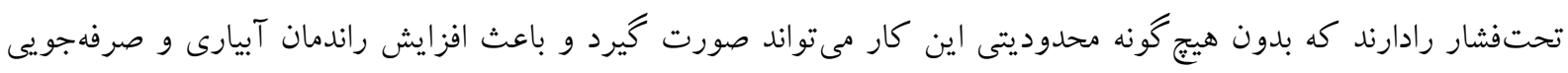

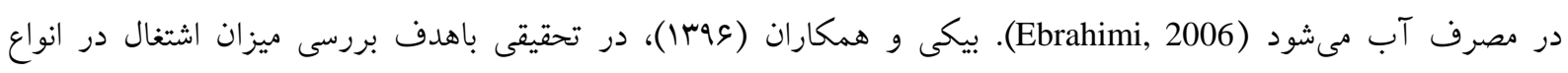

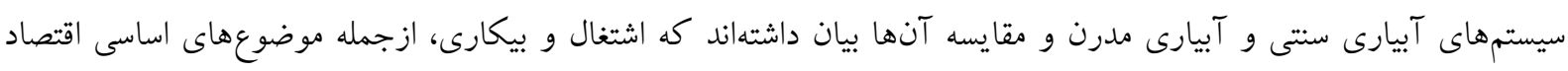

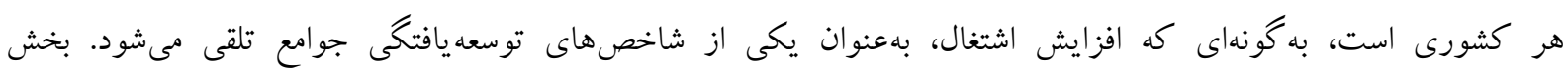

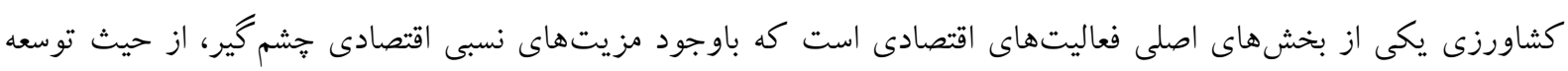

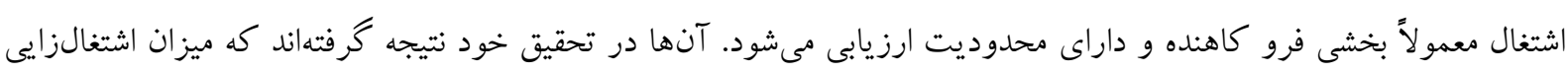

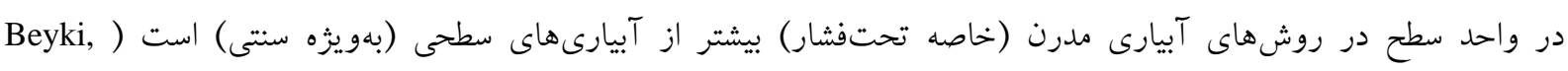

.(Pordel, Khashaei, \& Dasturati, 2017

يكى از مهمترين اهداف ارزيابى اراضى، بيشبينى نتيجه تغييرات در نوع استفاده از اراضى يا نحوهى اداره كردن اراضى

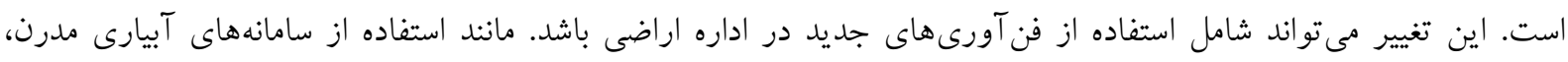

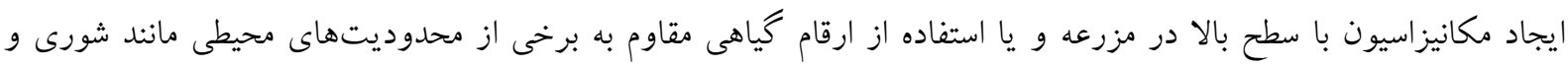

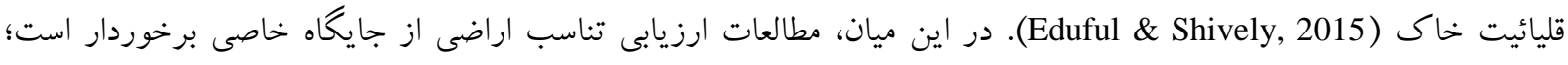

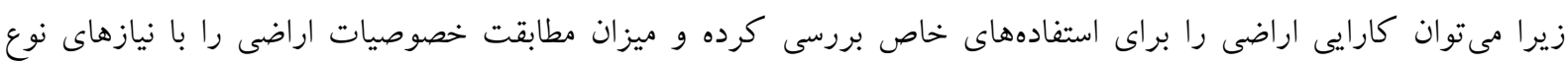

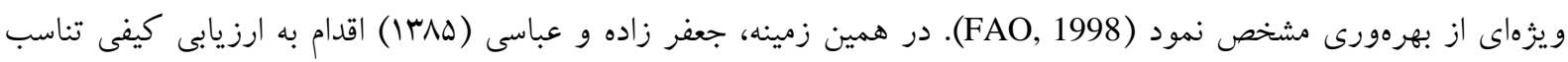

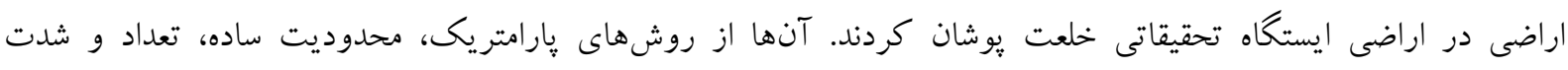

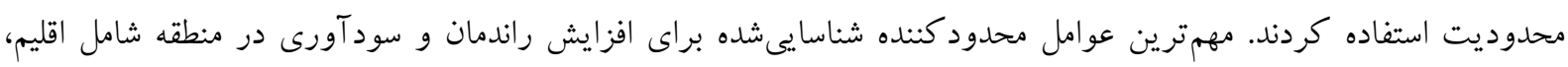

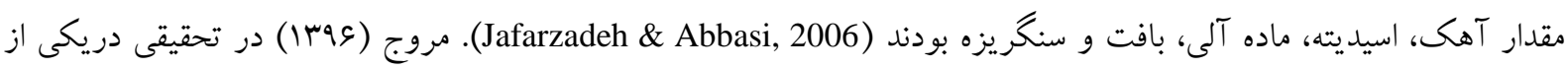

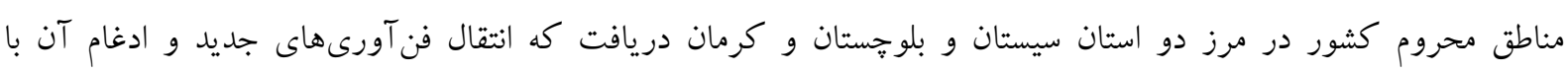

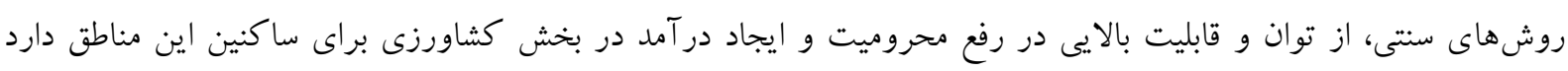
(Moravej, 2017)

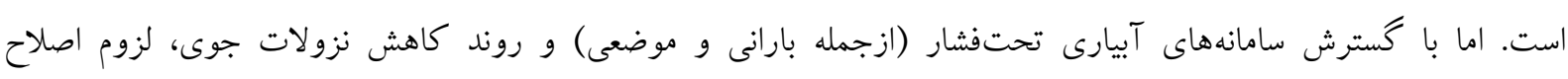

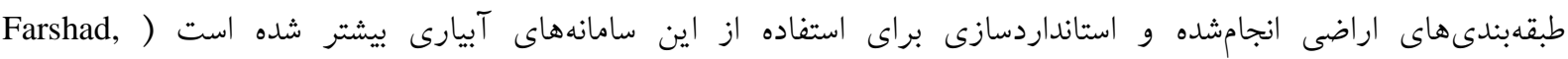
Mohammadi, \& Masihabadi, 2015

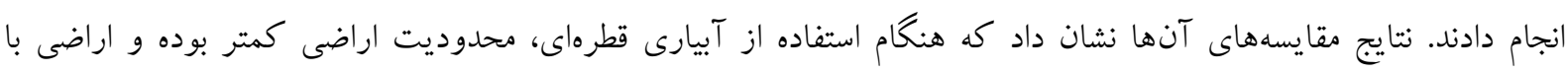
درجه بالاتر، مساحت بيشترى خواهند داشت (M Albaji, Landi, Nasab, \& Moravej, 2008).

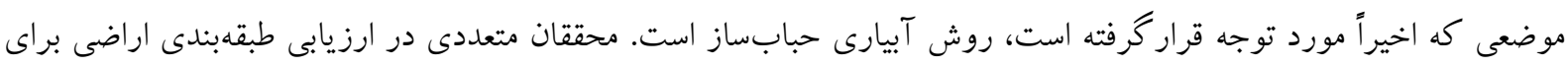

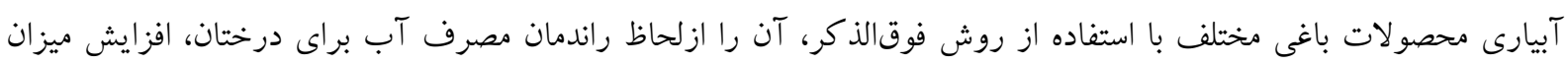


ת / NVA عملكرد و كيفيت محصولات بهدست آمده، روشى مناسب گزارش كرده و استفاده از اين روش رادر مناطق با منابع آب محدود توصيه نمودند (Khalifa \& Ali, 2015; Waller \& Yitayew, 2016El-Gindy, Mahmoud, \& Mohamed, 2016). در اين روش آبيارى، تِخش آب بر سطح خاك بهصورت يك جريان باريك حبابى شكل از منفذى با دبى بيشتر از آبدهى آبيارى

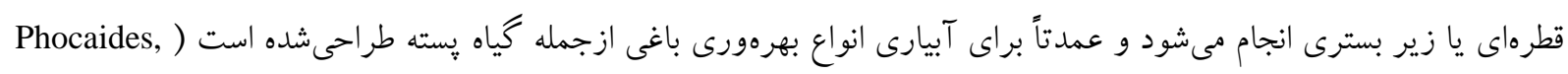

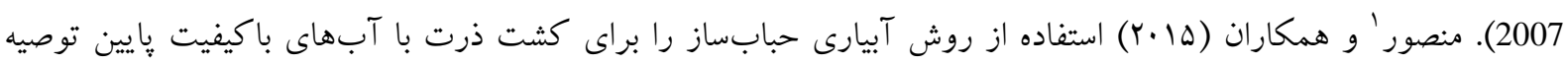

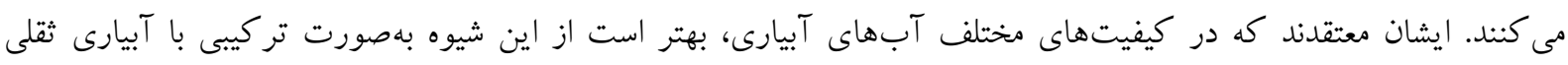

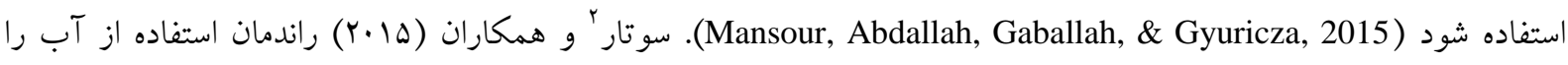

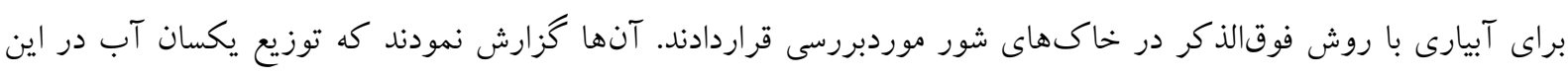

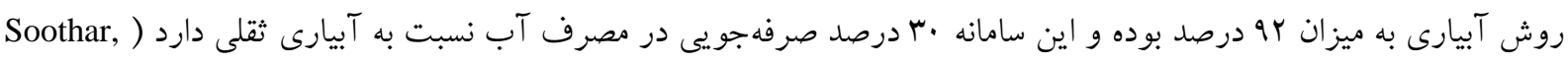

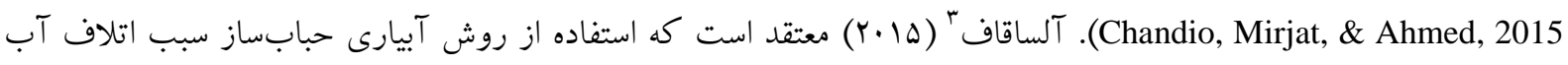

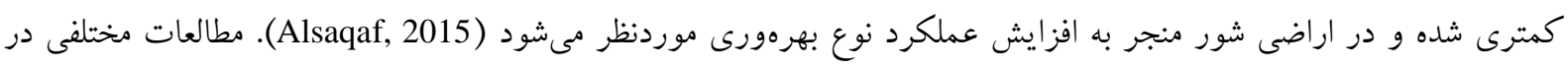

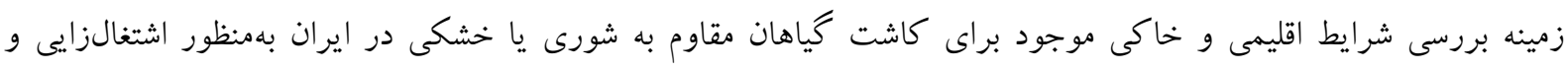

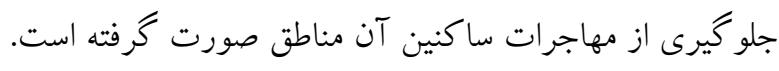

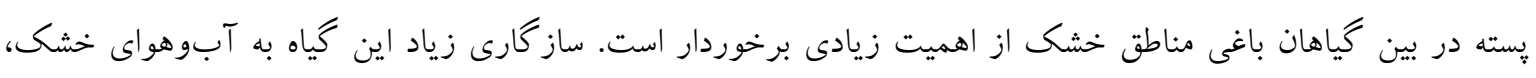

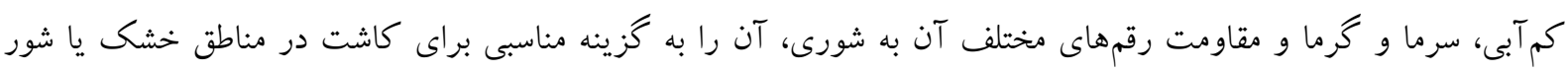

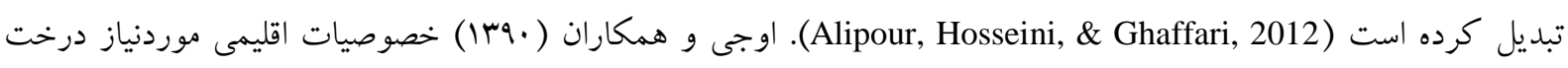

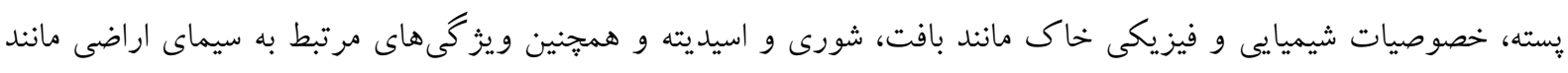

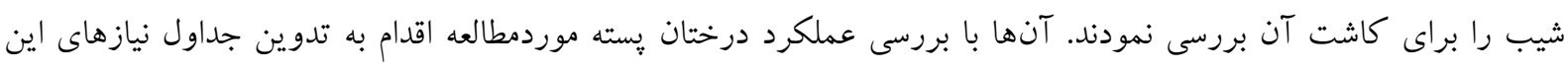

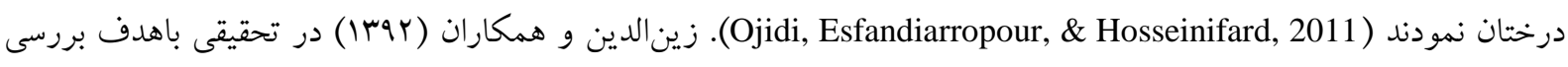
تحول، ردهبندى و خصوصيات فيزيكى و شيميايى خاكهاى تحت كشت بسته دشت سيرجان در استان كرمان دريافتند كه از

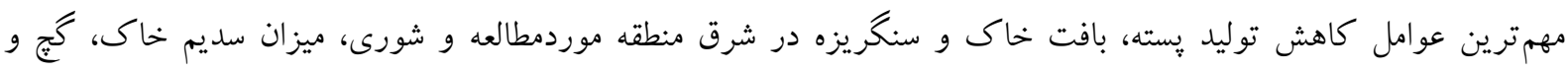

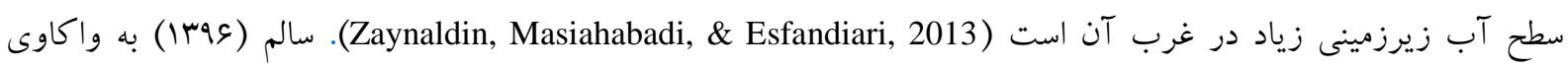

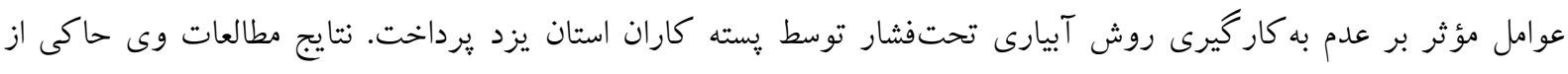

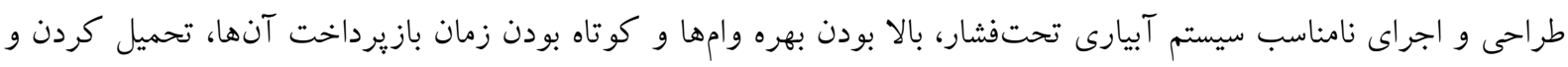

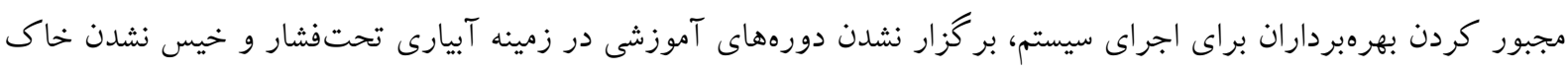

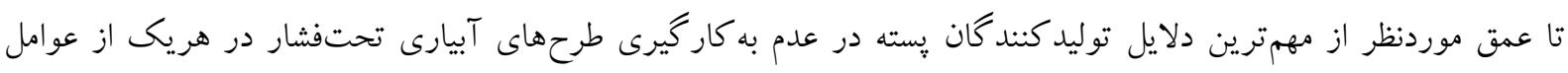

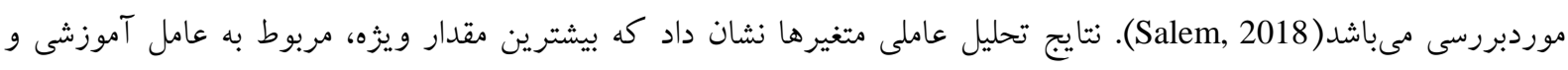

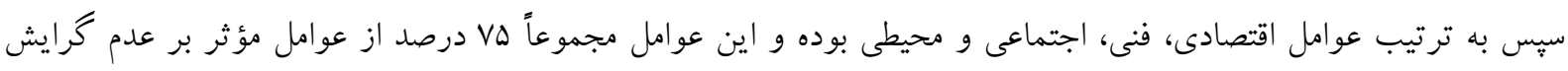

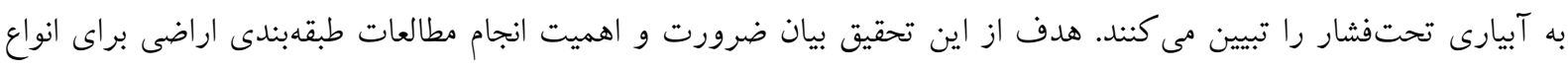

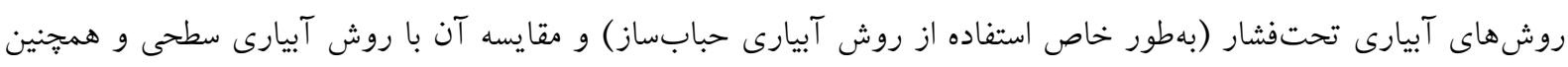


تأثير جايخزينى روش آبيارى مورداشاره در طبقهندى تناسب اراضى براى ايجاد اشتغال در مناطق روستايى و ممانعت از مهاجرت آنها ضمن كسب در آمد مىباشد.

مواد و روشها

تشريح وضعيت منطقه مطالعاتى

منطقه موردبررسى قسمتى از اراضى واقع در جنوب شهرستان ورامين در استان تهران مىباشد. اين منطقه در يك محدوده

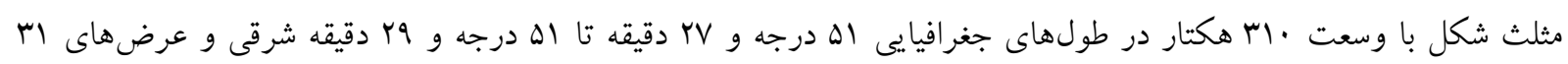

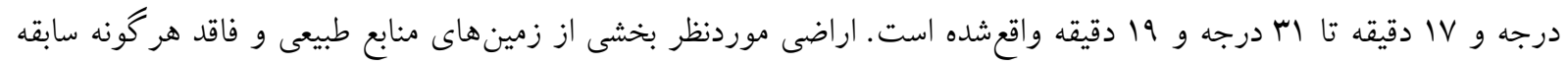

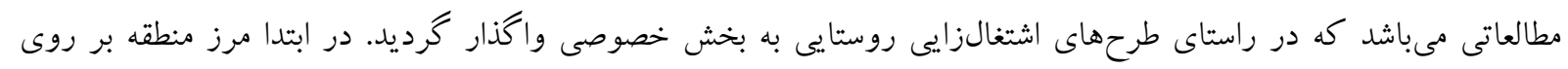

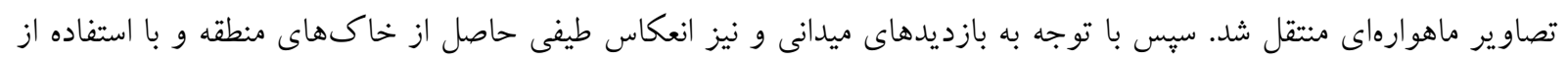

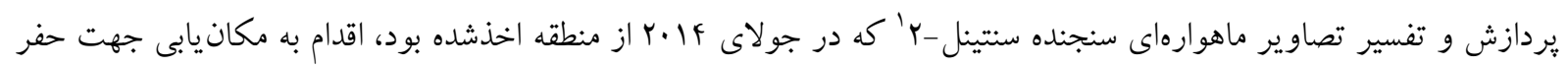

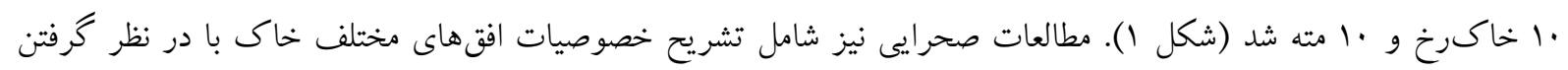

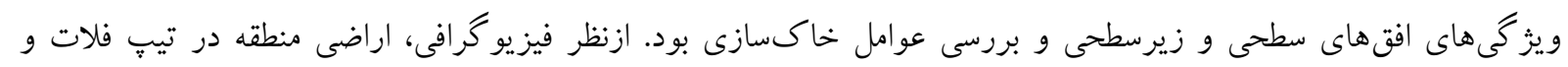

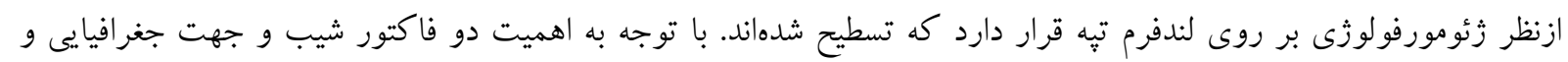

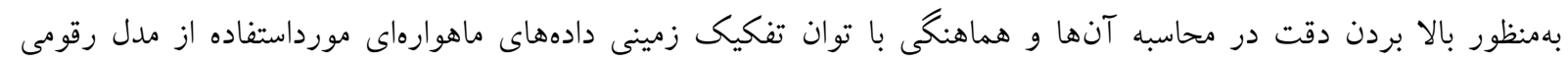

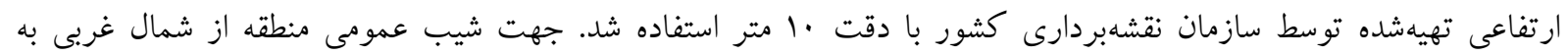

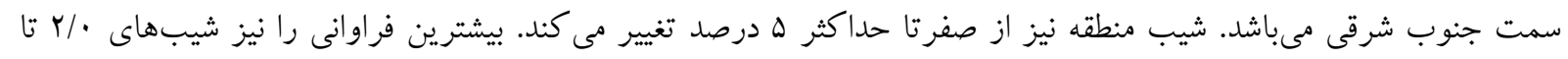
\%

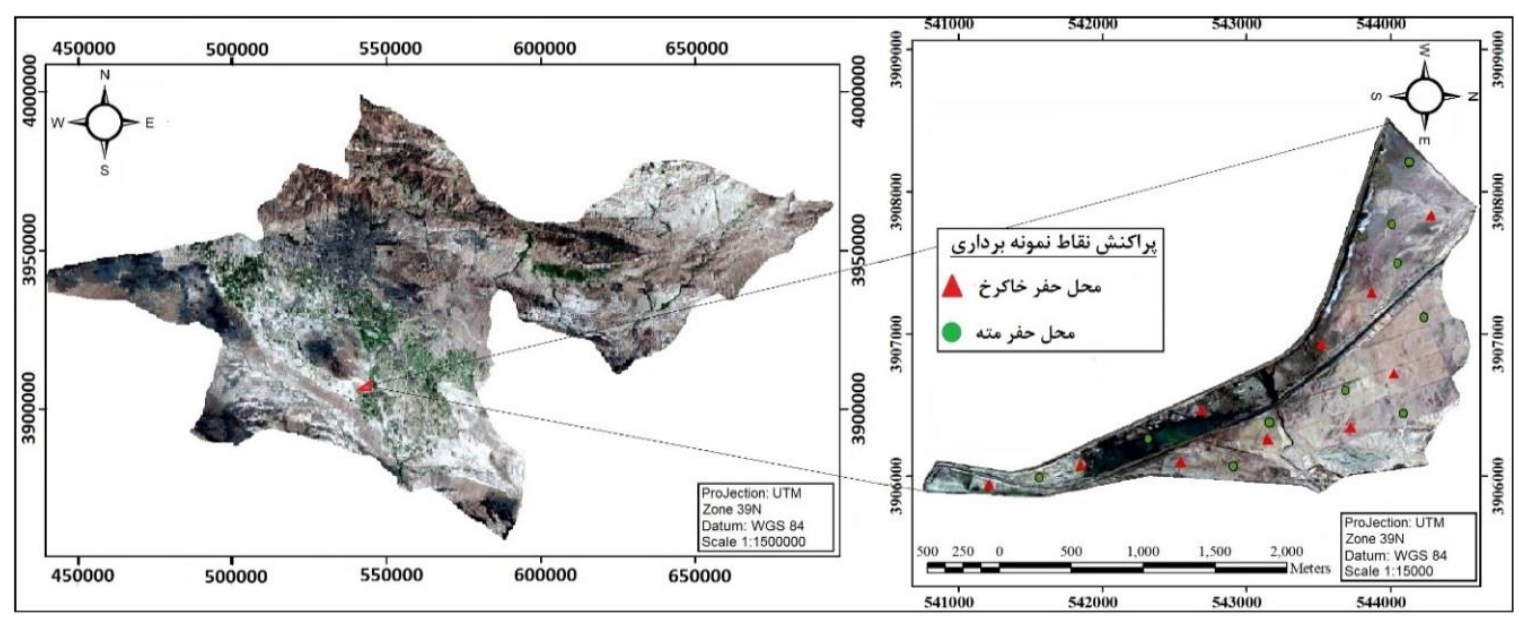

شكل ا- تصوير ماهوارهاى استان تهران (سمت جٍ) و تصوير ماهوارهاى منطقه موردمطالعه (سمت راست) زمين شناسى

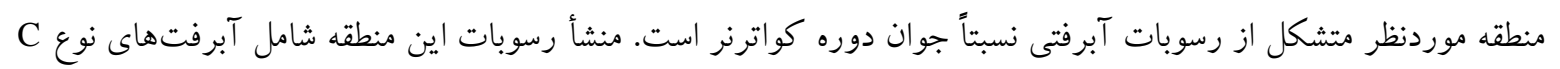

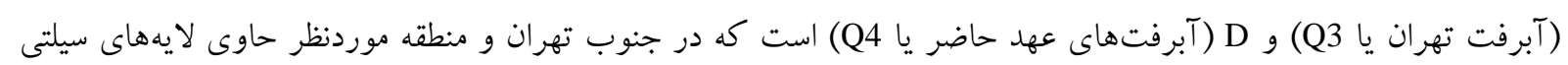




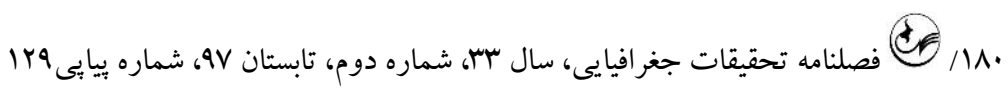
مىباشد. آبرفتهاى نوع D از جوانترين رسوبات رودخانه هاى سيلابى در ناحيه تهران است. اين رسوبات در شمال تهران شامل

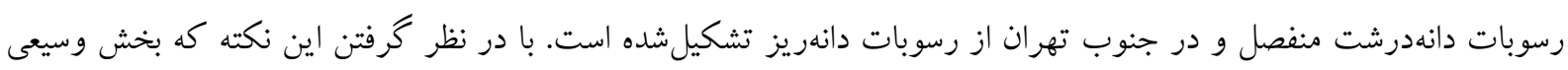

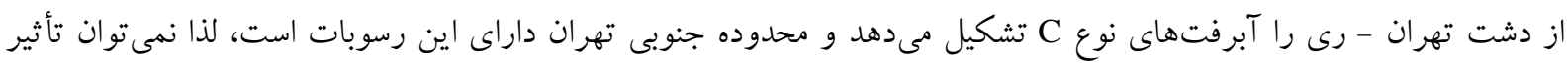

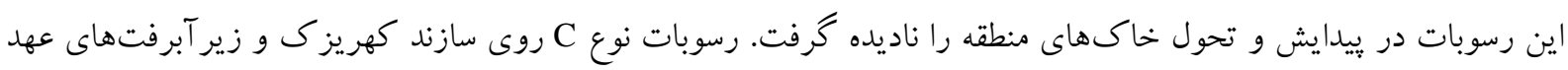

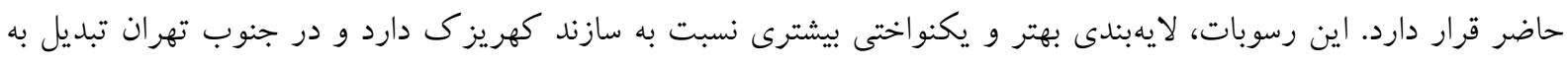

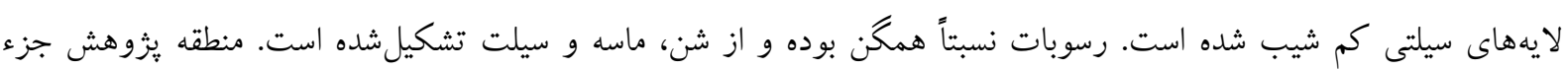

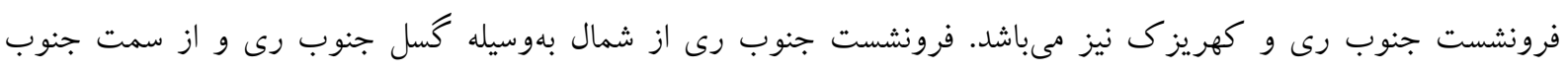

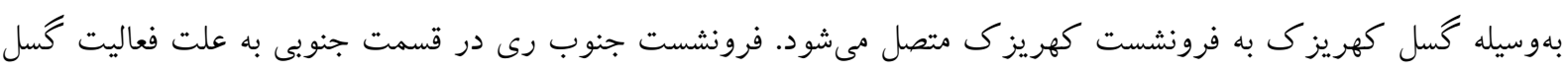

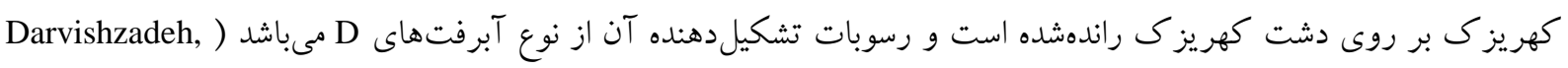

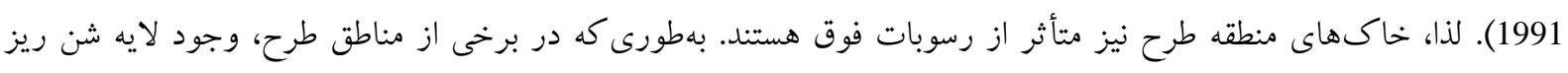

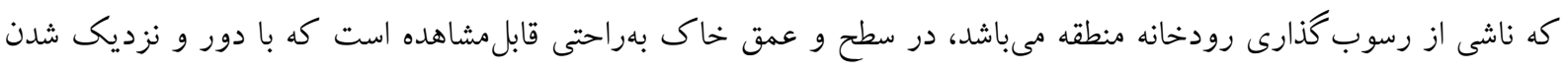
از رودخانه، عمق آن نيز تنيير مى كند.

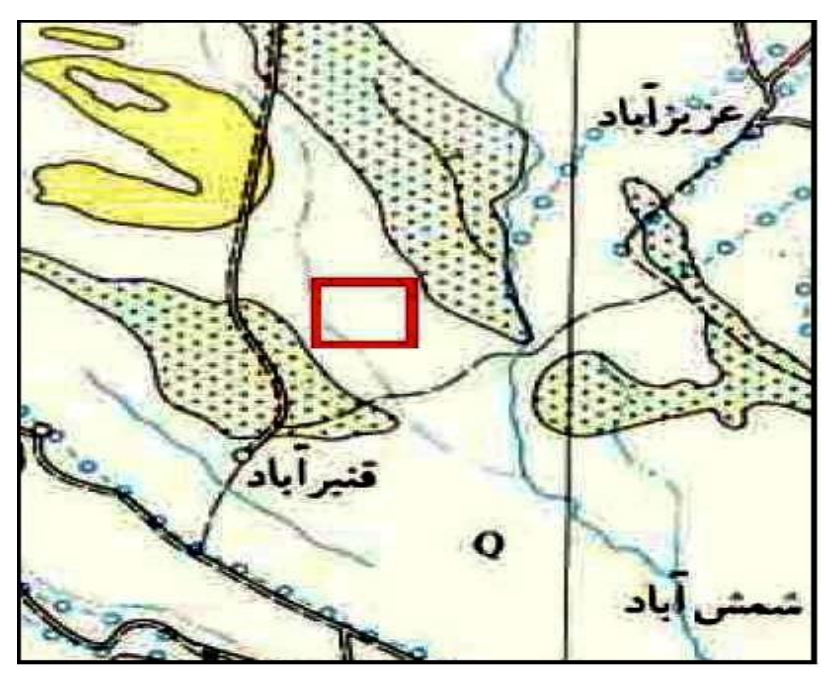

شكل r- موقعيت منطقه بر روى نقشه زمينشناسى استان تهران

رزيم رطوبتى و حرارتى منطقه

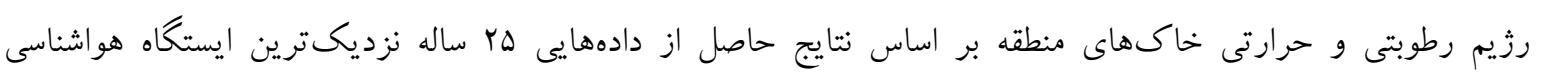

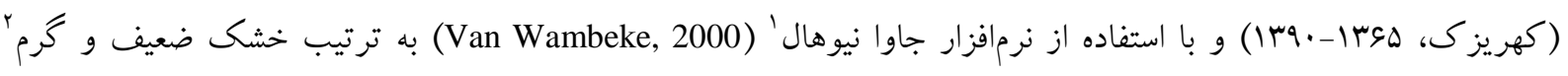

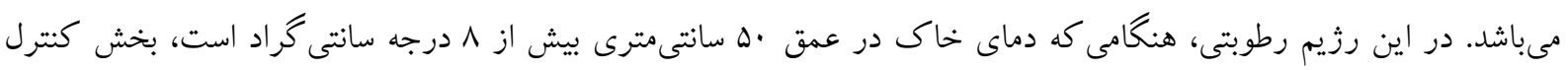

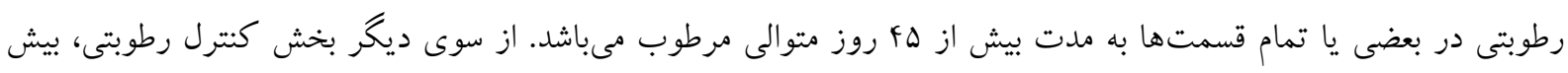

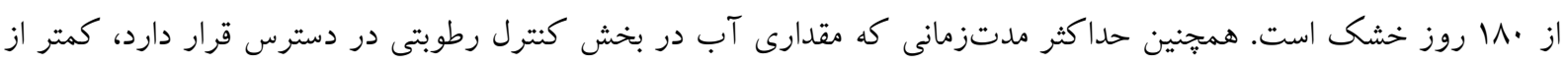

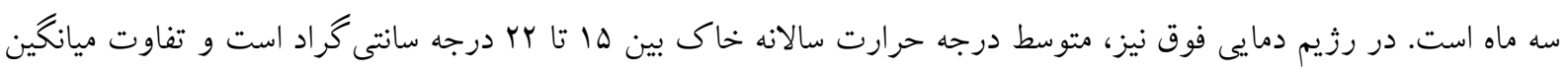

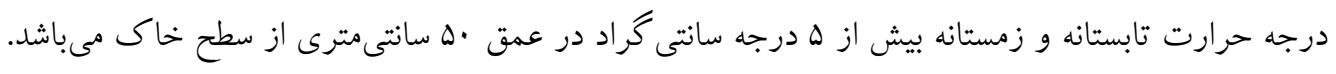




\section{تجز يههاى فيزيكى و شيميايى نمونههاى خاك}

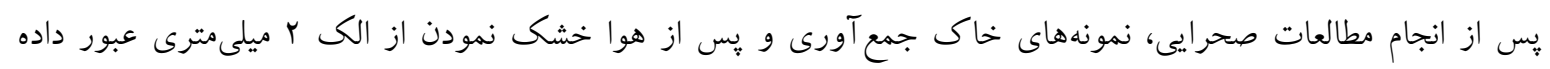

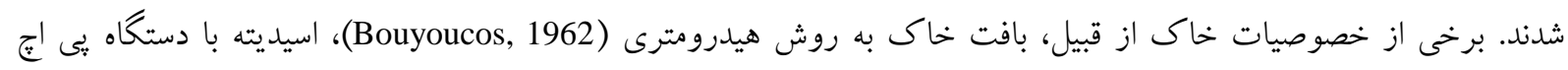

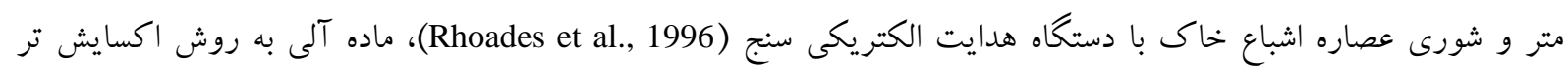
واكلى و بلك (Nelson, 1982)، آهك كل خاك با روش عاره باء كلسىمترى (Burt, 2004)، سديم با روش فليمفتومتر و كاتيونهاى

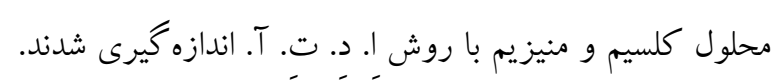

تشريح خصوصيات فيزيكى و شيميايى ثروفيل هاى خاك منطقه

بعد از اخذ نتايج تجزيههاى آزمايشگاهى و تحليل آنها، خاك ها بر اساس روش جامع (Soil Survey Staff, 2014)،

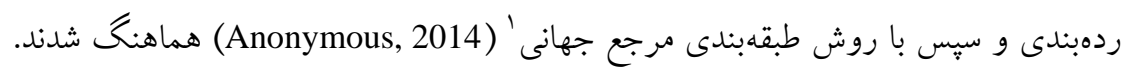

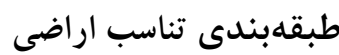

در اين يزوهش، تناسب كيفى اراضى با استفاده از درجهبندى محدوديتها و تعيين مقادير عددى شاخص براى درجات

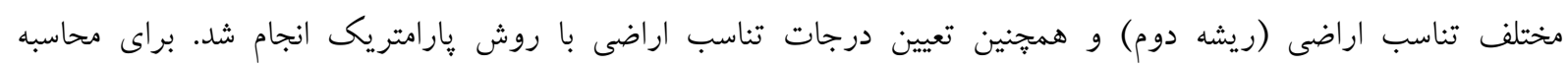

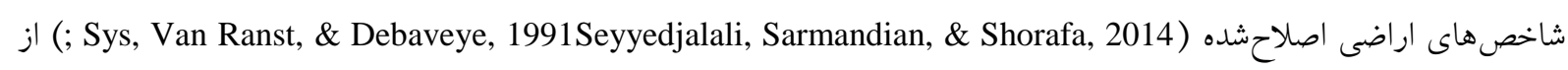
خصوصيات اقليمى، خاك و زمين موردنياز براى نوع بهرهورى يسته با توجه به به نتايج ساير محققين و منابع استفاده شد Khidir, ) (Ghaemian \& Najari, 2013)

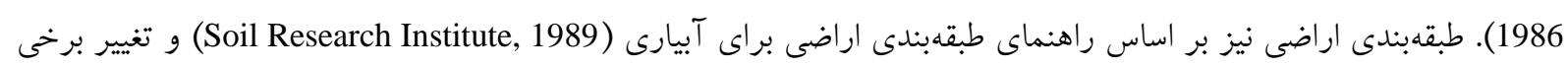

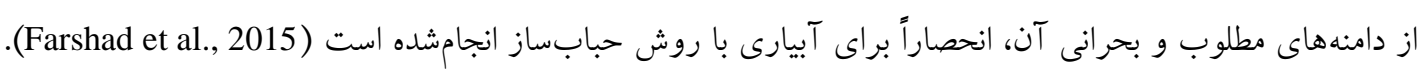

\section{مشخصات كلى خاكها}

جدول ا نتايج تجزيههاى آزمايشگاهى خصوصيات فيزيكى و شيميايى خاكرخخهاى شاهد منطقه را نشان مىدهد. يس از از

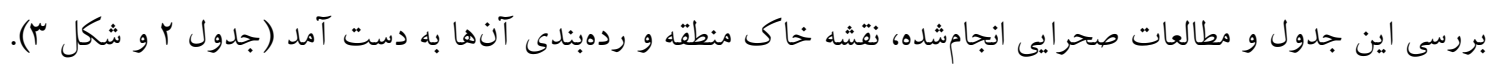
طبقهبندى اراضى براى آبيارى

\section{طبقهبندى اراضى براى آبيارى با روش ثقلى}

نتايج نهايى طبقهبندى حالتهاى سرىهاى مختلف اراضى براى آبيارى ثقلى در شكل \& ارائهشده است. در اين طبقهبندى،

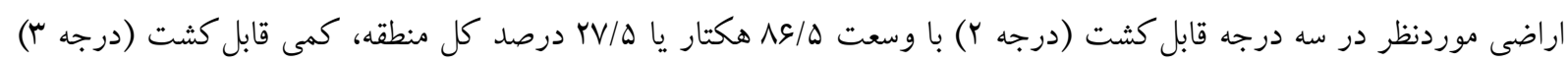

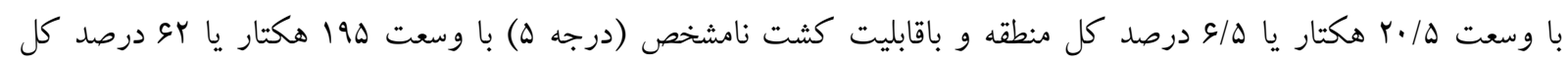

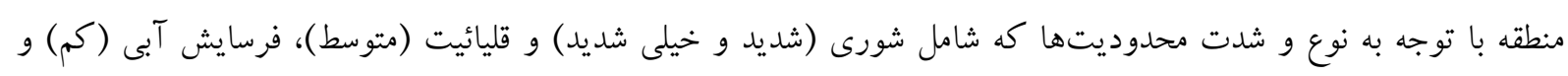




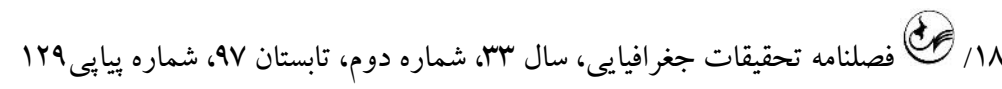
خطر سيل گيرى (متوسط) است، قرار گرفتند. مابقى وسعت منطقه جزء اراضى متفرقه قرار دارند. از مجموع كل مساحت منطقه،

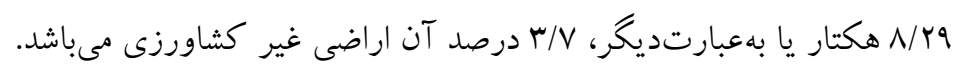

جدول 1- خصوصيات مورفولوزيكى، فيزيكى و شيميايى خاكسرخهاى شاهد

\begin{tabular}{|c|c|c|c|c|c|c|c|c|c|c|}
\hline \multirow{2}{*}{ نسبت جذب } & \multirow{2}{*}{$\begin{array}{l}S_{0} T \\
(\%)\end{array}$} & \multirow{2}{*}{ مواد آلى } & \multirow{2}{*}{ 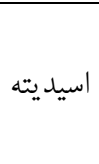 } & \multirow{2}{*}{$\begin{array}{c}\text { هدايت الكتريكى } \\
\left(\mathrm{dS} . \mathrm{S}^{-1}\right)\end{array}$} & \multirow{2}{*}{ خافت } & \multicolumn{3}{|c|}{ ذرات خاكى (درصد) } & \multirow[b]{2}{*}{ افق } & \multirow{2}{*}{$\begin{array}{l}\text { عمق } \\
(\mathrm{cm})\end{array}$} \\
\hline & & & & & & سيلت & شن & 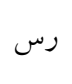 & & \\
\hline \multicolumn{11}{|c|}{ خاكرخ شاهد سرى خاك قنبر آباد 1، شيب كلى اراضى ·/1- درصد و يستىوبلندى كم } \\
\hline$V / \Delta$ & 10 & $\cdot / \cdot f$ & $V / 9$ & $\Delta / f$ & L. & $r M / \Delta$ & $F Y / D$ & ש & A & $\cdot-t r$ \\
\hline $4 / 9$ & ir & $\cdot / 1$ & $\mathrm{~V} / \mathrm{V}$ & $\Delta / \mu$ & L. & 荭 & $F N / D$ & rA & $\mathrm{C} 1$ & $r r-\omega$. \\
\hline$F / \Lambda$ & ir & $\cdot / r$ & $V / \varepsilon$ & $\Delta / 1$ & Si.L. & $19 / 0$ & $r$. & $\Delta \cdot / \Delta$ & $\mathrm{C} 2$ & $\Delta \cdot-\Lambda \cdot$ \\
\hline$V / r$ & 11 & $\cdot / \cdot r$ & $V / F$ & $F / \Lambda$ & L. & $r \Delta / \Delta$ & re/d & $\mu$ & $\mathrm{C} 3$ & $\Lambda \cdot-1 \cdot a$ \\
\hline $\mathrm{Q} / \cdot$ & 1. & $\cdot / 1$ & $V / \mu$ & $F / \mu$ & Si.L. & re & rr & $\Delta r$ & $\mathrm{C} 4$ & $1 \cdot \Delta-1 \omega_{\Delta}$ \\
\hline \multicolumn{11}{|c|}{ 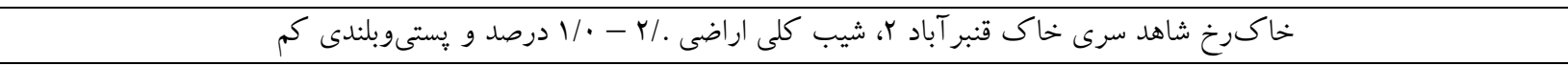 } \\
\hline rr & 9 &.$/ 148$ & $\Lambda / r$ & $\mu$ & L. & $r \mu / D$ & $F N / D$ & 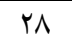 & $\mathrm{Az}$ & $\cdot-1 \mathrm{~V}$ \\
\hline rl & 9 & $\cdot / \cdot r q$ & $\Lambda / \mu$ & YN/V & Si.L. & $11 / 0$ & $r \omega / \Delta$ & dr & $\mathrm{Cz} 1$ & IV -r. \\
\hline 11 & $\wedge$ & $\cdot / 1 F E$ & $\Lambda / 1$ & $r \Delta / /$ & Si.L. & $r / \Delta$ & $r r / D$ & sf & $\mathrm{Cz} 2$ & r.-q. \\
\hline if & V & $\cdot / \cdot 4 \Lambda$ & $\mathrm{V} / \mathrm{\Lambda}$ & $r M / r$ & Si.L. & $r / \Delta$ & $F Y / D$ & $\Delta F$ & $\mathrm{Cz} 3$ & $s \cdot-\Lambda \cdot$ \\
\hline 11 & $\Delta$ & $\cdot / \cdot+\Lambda$ & $V / V$ & $1 \varepsilon / f$ & L.S. & $\Delta / \Delta$ & $\Lambda \varepsilon / \Delta$ & $\wedge$ & $\mathrm{C} 1$ & $\Lambda \cdot-11$ \\
\hline 9 & $\Delta$ &.$/ \cdot r q$ & $V / V$ & $9 / 1$ & S. & $1 / 0$ & $9 F / D$ & F & $\mathrm{C} 2$ & $11 \cdot-1 Y \Delta$ \\
\hline V & a & $\cdot / \cdot s \Lambda$ & $V / \varepsilon$ & $\Delta / r$ & L. & $r M / D$ & $F \& / D$ & rr & C3 & $1 r \Delta-1 \Delta$. \\
\hline \multicolumn{11}{|c|}{ خاكرخ شاهد سرى خاك قنبر آباد r، شيب كلى اراضى ه - r درصد و يستىوبلندى كم } \\
\hline$r \cdot / V$ & $\wedge$ & .1 .9 & $N / F$ & $M / \Lambda$ & Si.L. & $\Delta / \Delta$ & $r \varepsilon / D$ & s^ & $\mathrm{Az}$ & $\cdot-r Y$ \\
\hline $\mid s / 1$ & V & $\cdot / \cdot V$ & $N / r$ & $M F / F$ & Si.L. & $r / \Delta$ & $r \cdot / \Delta$ & sq & $\mathrm{Cz} 1$ & $M Y-F D$ \\
\hline$\Lambda / V$ & V &.$/ \cdot F$ & $\mathrm{~V} / \mathrm{\Lambda}$ & $1 r / F$ & S. & $r / \Delta$ & $\Lambda \mathrm{V}$ & $9 / 0$ & $\mathrm{Cz} 2$ & $F \Delta-g r$ \\
\hline$\Lambda / 1$ & $\Delta$ & $\cdot / \cdot 0$ & $V / V$ & $1 \cdot / r$ & S.L. & $r / \Delta$ & $S Y / D$ & ry & $\mathrm{C} 1$ & $s r-\Lambda$. \\
\hline$s / r$ & $\Delta$ & .1 .9 & $V / V$ & $1 \cdot / 9$ & Si.L. & $r / \Delta$ & $F F / D$ & $\Delta r$ & $\mathrm{C} 2$ & $\Lambda \cdot-1 \cdot \Delta$ \\
\hline$r$ & $\Delta$ & $\cdot / \cdot V$ & $V / \Delta$ & $\Delta / 9$ & L. & $\Delta / \Delta$ & $18 / 0$ & V^ & $\mathrm{C} 3$ & $1 \cdot \Delta-1 Y \Delta$ \\
\hline
\end{tabular}

جدول r- هماهنغى و ردهبندى خاكتهاى منطقه موردمطالعه

\begin{tabular}{|c|c|c|c|c|c|}
\hline ردهبندى طبق روش & فاميلى طبق & تحت گروه & | ا & سرى & شكل اراضى \\
\hline Calcaric Fluvisols & Fine loamy, mixed, thermic & $\begin{array}{l}\text { Typic } \\
\text { Torrifluvents }\end{array}$ & Entisols & ق ق قبن آباد ا & \multirow{3}{*}{ فلات } \\
\hline Salic Fluvisols & $\begin{array}{l}\text { Coarse loamy over sandy, } \\
\text { mixed, thermic }\end{array}$ & $\begin{array}{l}\text { Typic } \\
\text { Torrifluvents }\end{array}$ & Entisols & ق ق قبر آبادץ & \\
\hline Salic Fluvisols & $\begin{array}{l}\text { Coarse loamy over sandy, } \\
\text { mixed, thermic }\end{array}$ & $\begin{array}{l}\text { Typic } \\
\text { Torrifluvents }\end{array}$ & Entisols & 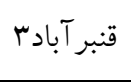 & \\
\hline
\end{tabular}




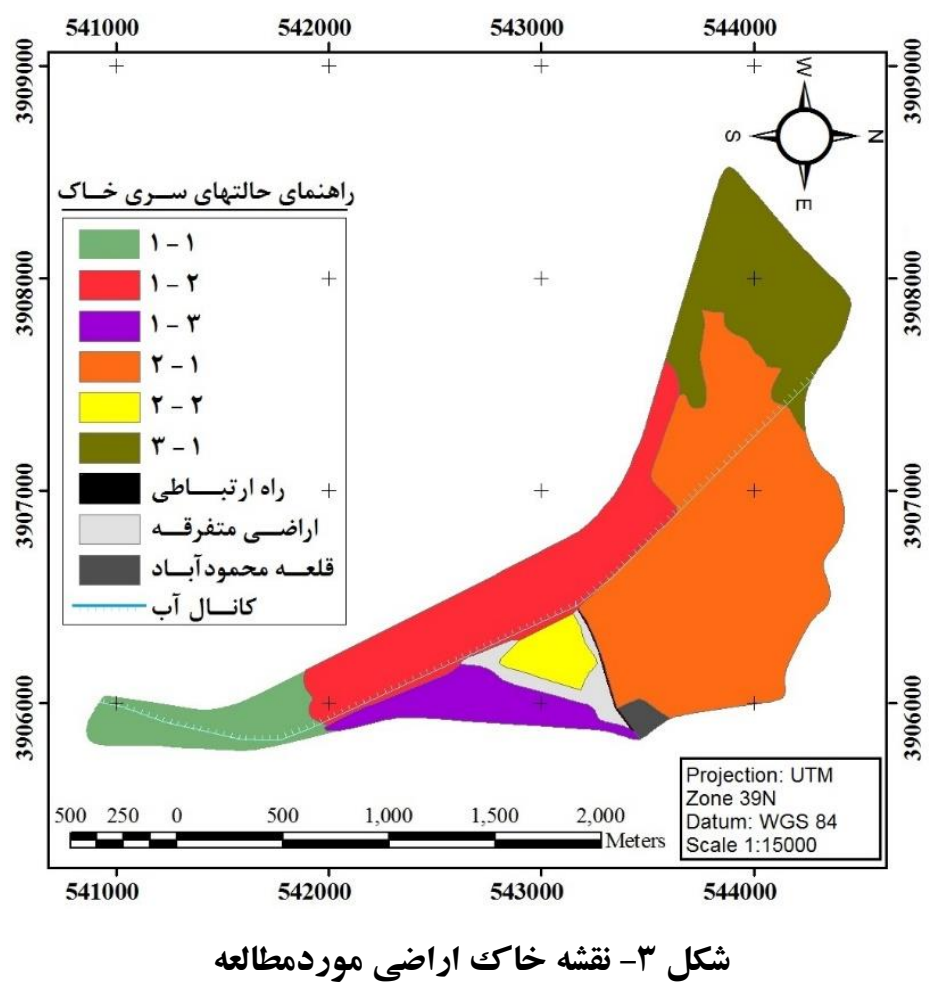

طبقهبندى اراضى براى آبيارى موضعى با روش حبابساز در مورد طبقهبندى اراضى براى آبيارى با روش حبابساز نيز، همجنان هوان هكتار يا باء درصد اراضى كل منطقه داراى

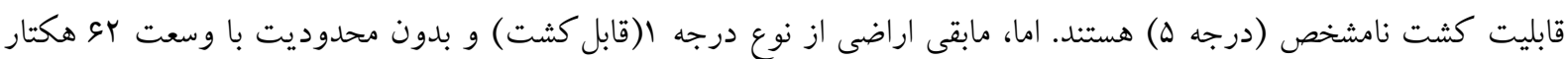

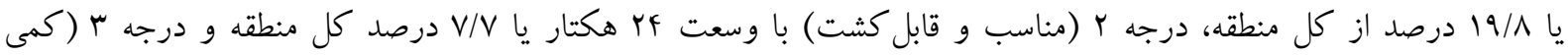

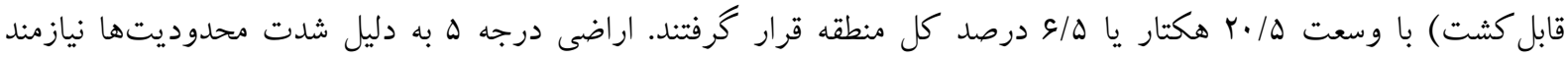

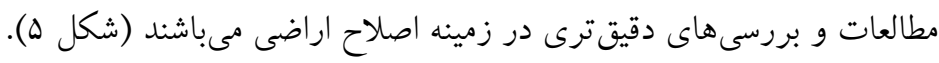
مقايسه نتايج طبقهبندى اراضى براى آبيارىهاى ثقلى و حبابساز با توجه به نتايج بهدست آمده از نقشه هاى طبقهبندى اراضى (اشكال f و ه ه)، با تغيير روش آبيارى از ثقلى به حبابساز، در

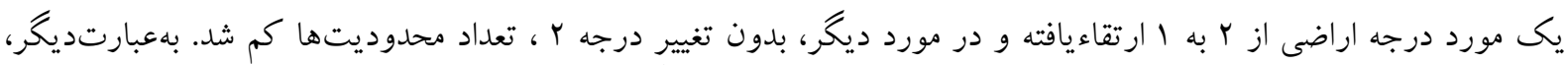
با تغيير روش آبيارى، فقط خطر سيل گيرى در سطح متوسط محدوديت ايجاد مى كند كه آنهم با احداث سيل بند و و كنترل سيل

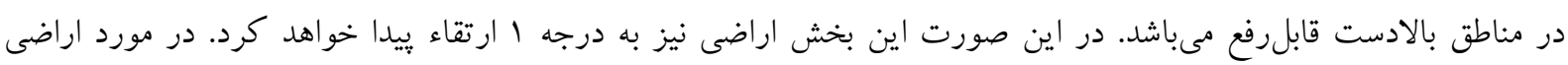

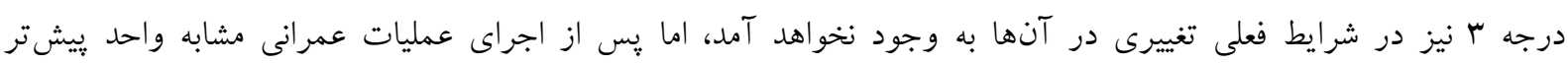

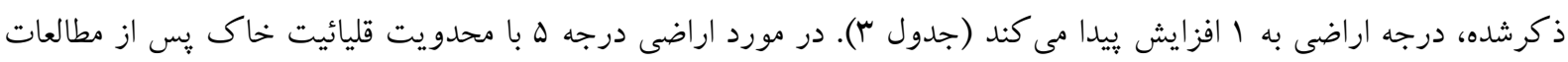

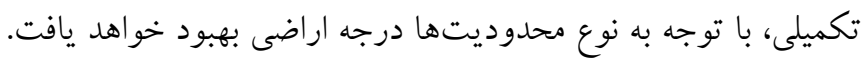


INAF

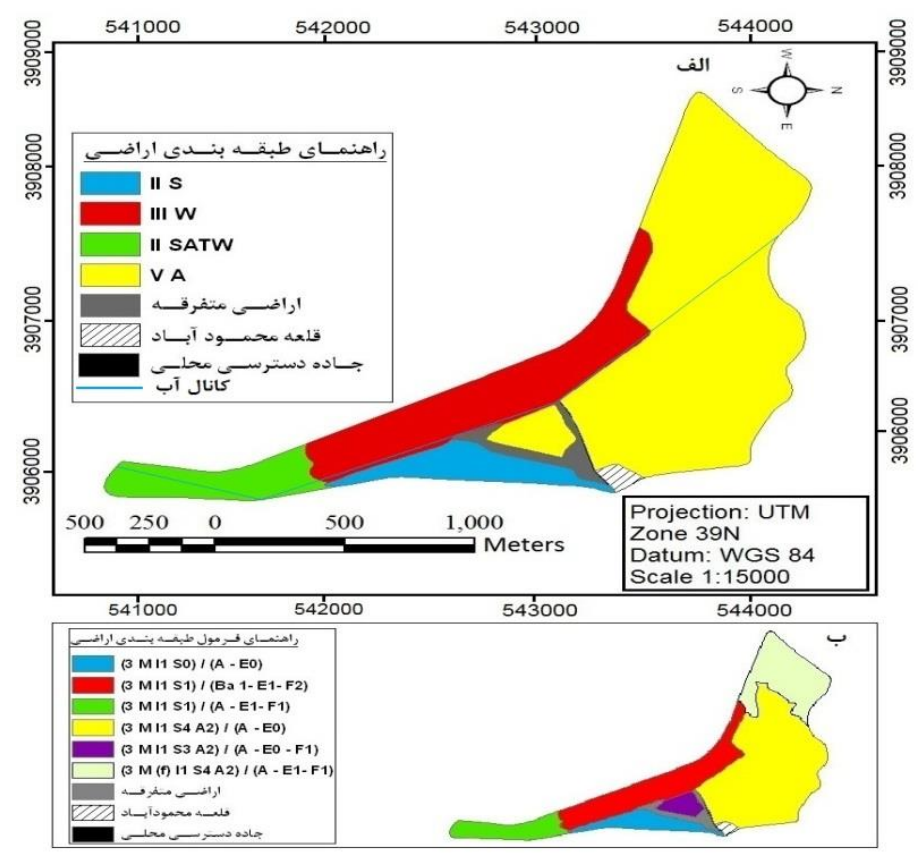

شكل ع- نقشه طبقهبندى اراضى براى آبيارى با روش ثقلى.

الف: درجه و زير درجه، ب: فرمول محدوديت

بعد از انجام مطالعات قابليت آبيارى اراضى و يس از رفع يا كاهش محدوديتهاى قابل اصلاح و و انجام عمليات عمرانى،

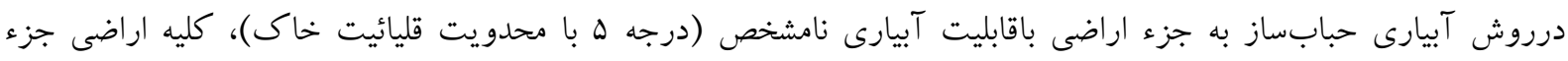

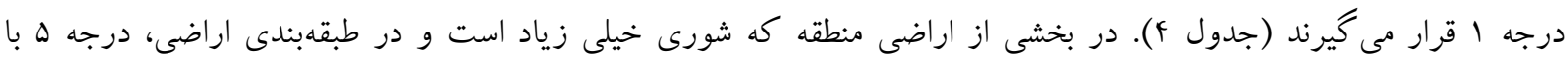

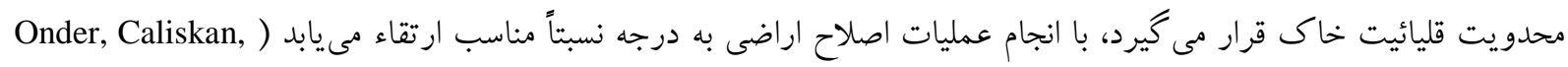

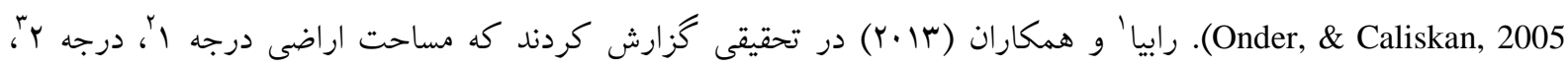

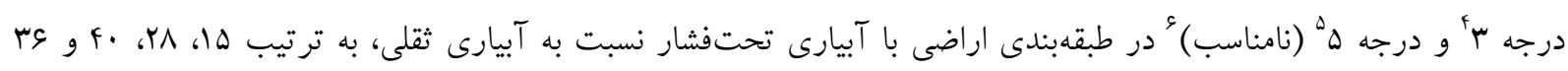

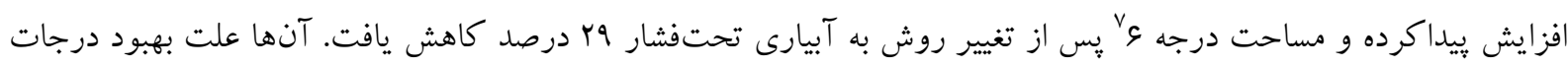

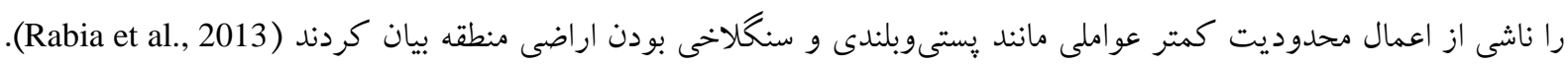

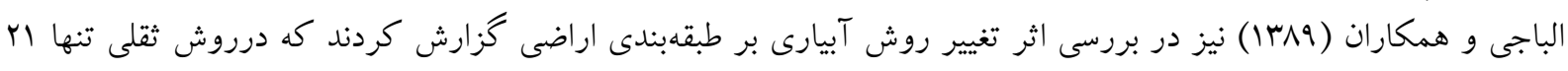

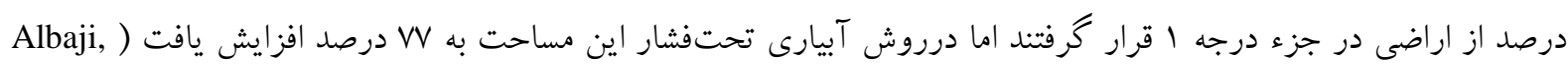




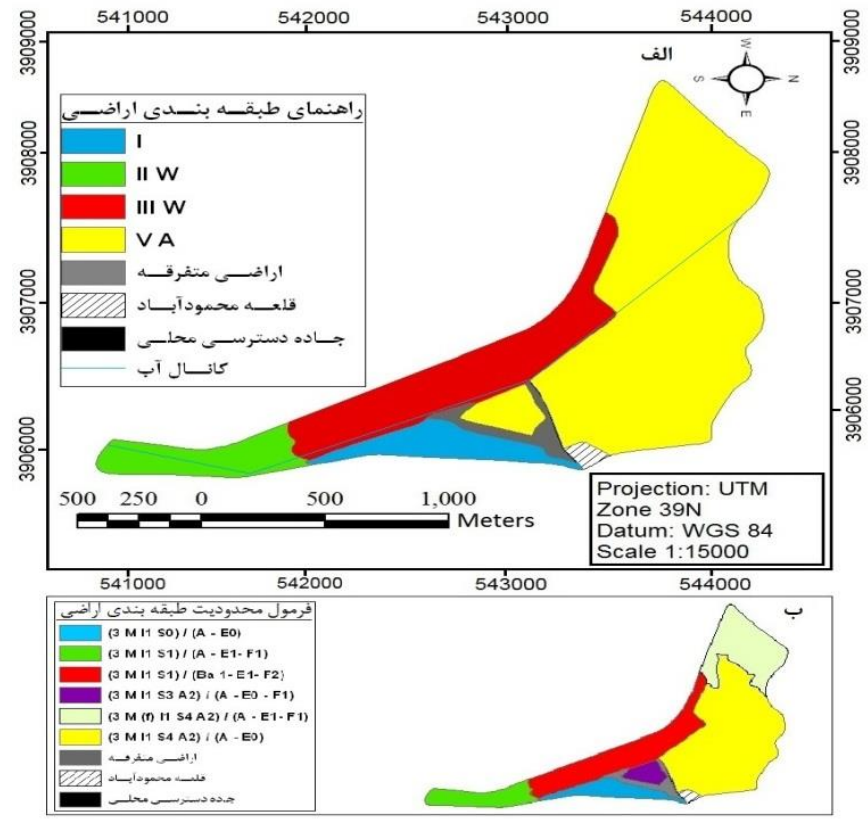

\section{شكل 0- نقشه طبقلبندى اراضى براى آبيارى با روش حبابساز الف: درجه و زير درجه، ب: فرمول محدوديت}

جدول r- مقايسه درجه و زير درجه اراضى در دو روش آبيارى

\begin{tabular}{|c|c|}
\hline 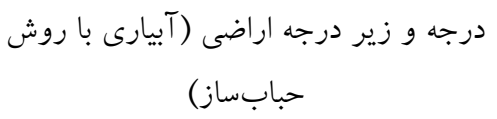 & درجه و زير درجه اراضى (آبيارى ثقلى) \\
\hline درجه I' & درجه r با محدوديت خصوصيات خاك' \\
\hline درجه r با محدوديت زهكشى & 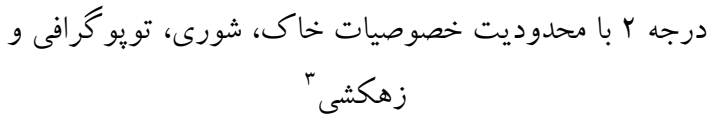 \\
\hline درجه س با محدوديت زهكشى & درجه س با محدوديت زهكشىه \\
\hline
\end{tabular}

جدول ع- ارتقاء درجه آيارى در آيارى با روش حبابساز يس از عمليات اصلاحى

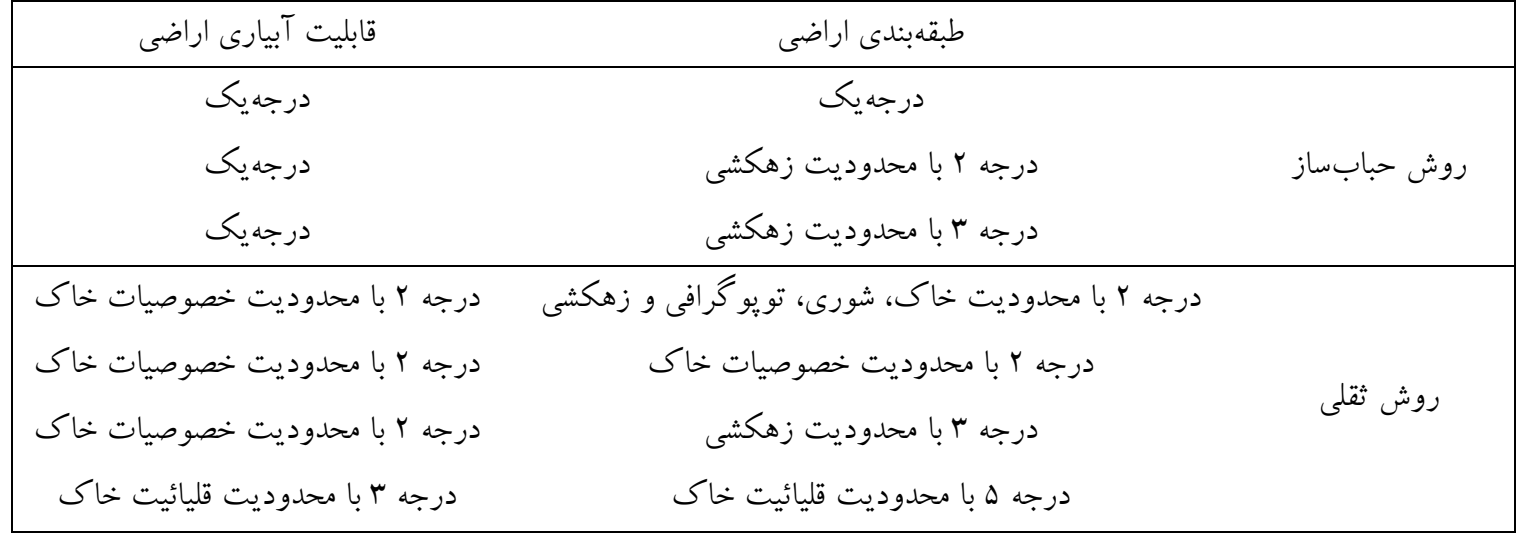




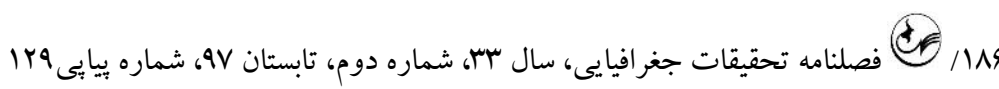
طبقهبندى تناسب اراضى براى درخت يسته همانطور كه ييشتر ذكر شد، اخيراً مناطق زيادى از كشور كه دهار مشكلات كم آبى و محدوديت خاك و اراضى هستند،

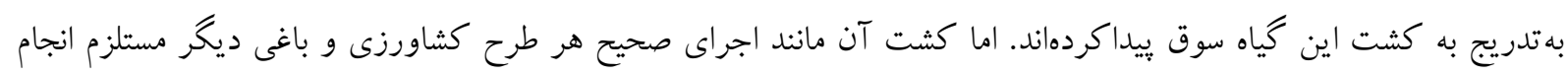

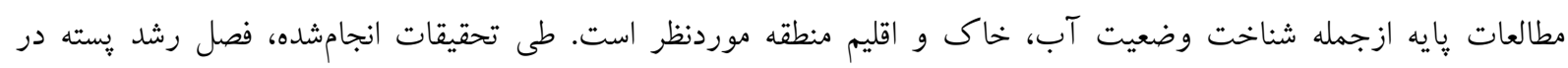

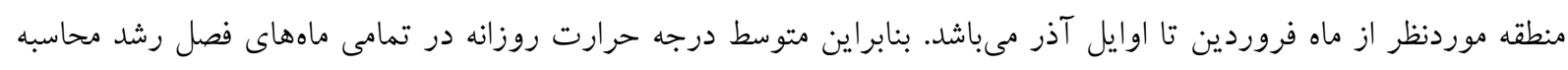

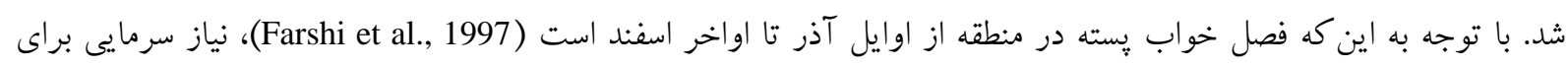

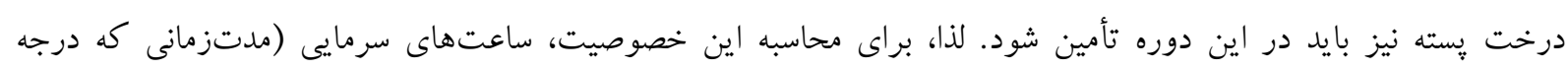

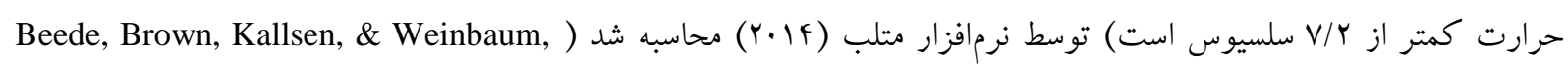

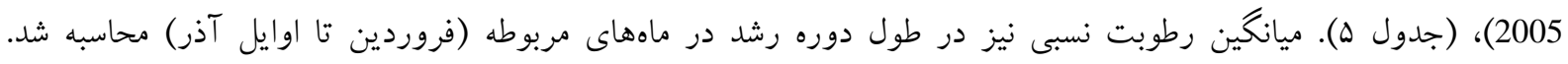

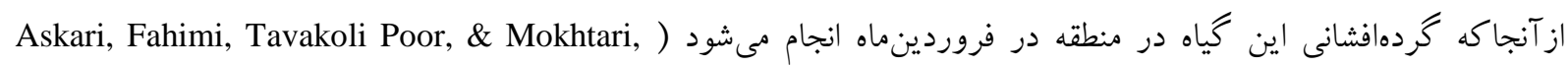

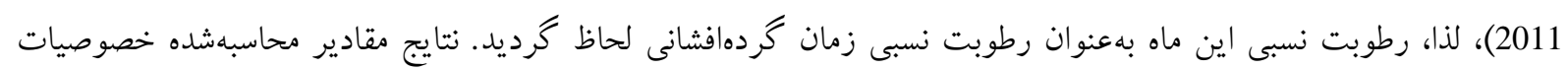

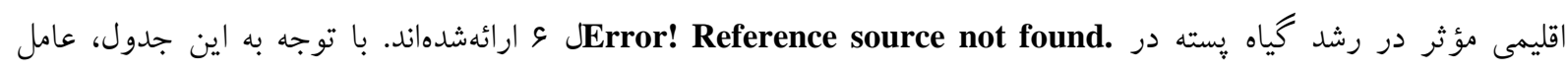

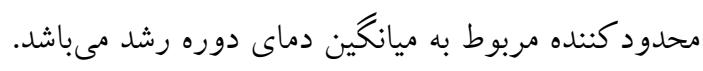

جدول 0- ساعتهاى سرمايى

\begin{tabular}{|c|c|c|c|c|c|c|c|c|c|c|c|c|}
\hline اسفند & بهمن & دى & آذر & آبان & مهر & شهريور & مرداد & تير & خرداد & ارديبهشت & فروردين & ماه \\
\hline $1 D S$ & 015 & DFT & F.Y & $q \mu$ & . & . & . & . & . & . & . & تعداد ساعت \\
\hline
\end{tabular}

جدول 7 - نتايج ارزيابى شاخص اقليم براى كاشت درخت يسته در منطقه موردمطالعه

\begin{tabular}{|c|c|c|c|c|c|}
\hline \multicolumn{2}{|c|}{ درجه نهايى } & \multicolumn{2}{|c|}{ درجه محدوديت } & \multirow{2}{*}{ مقدار محاسبهشده } & \multirow{2}{*}{ خصياز سرمايى(hr) } \\
\hline \multirow{4}{*}{ r } & \multirow{4}{*}{ sV } & 1 & $1 .$. & & \\
\hline & & r & $s V$ & ri & ميانكين دماى دوره رشد \\
\hline & & 1 & $1 \cdots$ & $\mu_{F}$ & رطوبت نسبى دوره رشد (\%) \\
\hline & & 1 & $1 \ldots$ & Fa & رطوبت نسبى در زمان كردهافشانى \\
\hline
\end{tabular}

ارزيابى تناسب خصوصيات خاك و اراضى

خصوصياتى از زمين مانند هِتىوبلندى و درصد شيب و خاك مانند بافت و ساختمان، هدايت الكتريكى، اسيديته، نسبت

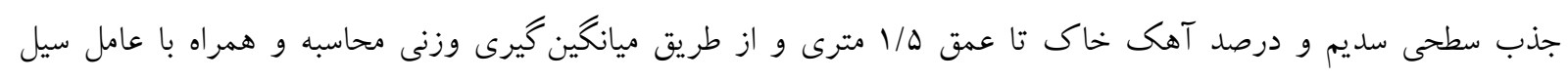

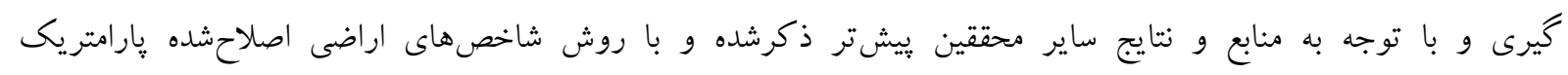
(; Sys et al., 1991Seyyedjalali et al., 2014)

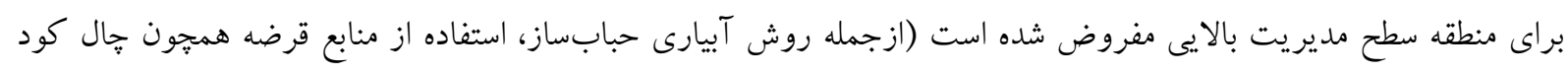

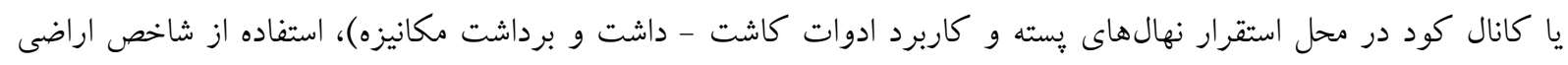

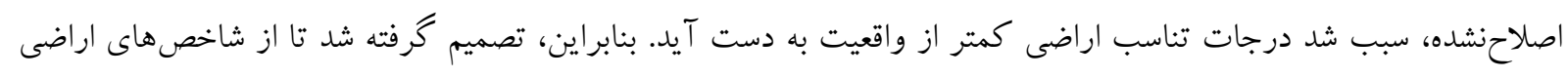

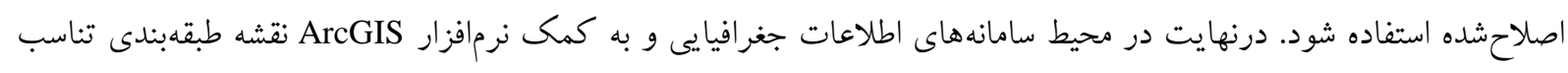

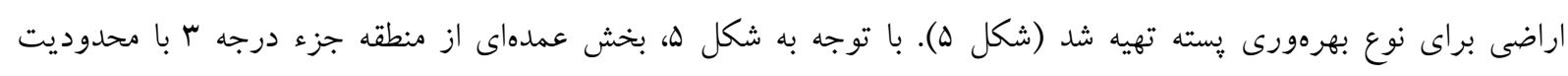


اهميت استفاده از روشهاى نوين آبيارى در افزايش اشتغالزايى و توسعه مناطق روستايى INV/

DOI:10.29252/geores.33.2.175

شورى خاكى قرار دارد و مابقى اراضى قابلمطالعه منطقه در درجات ب و نامناسب با محدوديت شورى خاك جاى گرفته است. محدوديت اصلى اين اراضى نيز عامل شورى خاك مىباشد. قائميان و رنجبرى (rar|) در مطالعه اراضى شور حاشيه درياجه اروميه براى كاشت ڤسته اظهار مى كنند، درجات يايين تناسب اراضى باوجود مقاومت نسبى اين گياه، ناشى از شورى بسيار

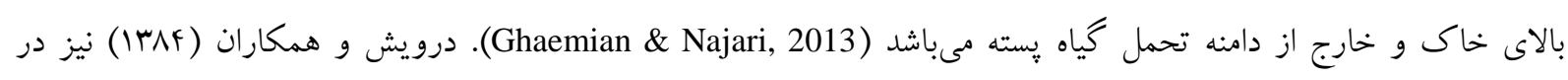
مناطق خشك و نيمه خشك موردمطالعه، مشكل شورى بالا را مهمترين محدوديت گياهان مختلف، ازجمله درختان مقاوم به شورى مانند يسته در شرايط سطح مديريت متوسط دانستند (Darwish, Atallah, El Moujabber, \& Khatib, 2005). همانطور

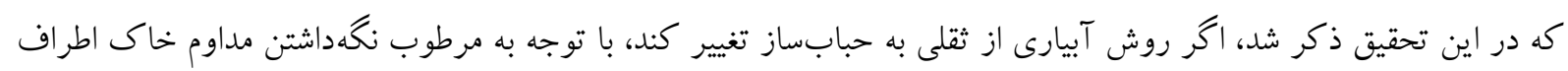
ريشه، امكان نفوذ نمك و املاح به محيط اطراف ريشه كاهش خواهد يافت و اثر تنش شورى كاهش بيدا مى كند. احمدى و برزكرى (·•وسا) در مقايسه آبيارى درختان يسته بهوسيله روش سطحى و قطرهاى به اين نتيجه رسيدند كه روشهاى نوين آبيارى نسبت به آبيارى سنتى سبب كاهش تنش شورى شده و باعث افزايش عملكرد مى شود (Ahmadi \& Barzgari, 2012).

جدول Y- شاخصهاى اصلاحشده براى نوع بهرهورى يسته و درجه تناسب اراضى براى هر يكى از حالتهاى سرى خاكى

\begin{tabular}{|c|c|c|c|c|c|c|c|c|c|c|c|}
\hline \multicolumn{11}{|c|}{ شاخص و درجه تناسب اراضى براى حالتهاى سرى خاك } & \multirow{2}{*}{ خصوصيات خاك و اراضى } \\
\hline & & & $-r$ & & & & r & & & $1-1$ & \\
\hline & & & f & & & & $\Delta$ & & & 91 & يستى وبلندى و شيب \\
\hline & & & $r$ & & & & $\Delta$ & & & V9 & سيل كيرى \\
\hline & & & f & & & & $r$ & & & 90 & خصوصيات خاك (بافت، عمق، ساختمان و مقدار سنكريزه) \\
\hline & & & $\Delta$ & & & & V & & & Fr & شورى (dS.m-1) \\
\hline & & & $\Lambda$ & & & & $r$ & & & VD & حاصلخيزى خاك (اسيديته) \\
\hline & & & $\Delta$ & & & & $\Delta$ & & & 99 & آهك (درصد) \\
\hline & & & $\Lambda$ & & & & $\Lambda$ & & & $\Lambda \Delta$ & نسبت جذب سطحى سديم1 \\
\hline N1 & 19 & S3 & FI & S3 & $r_{\Delta}$ & S2 & $V \cdot$ & S3 & $\mu_{f}$ & S3 rs & شاخص اصلاحشده و درجه تناسب اراضى نهايى \\
\hline
\end{tabular}

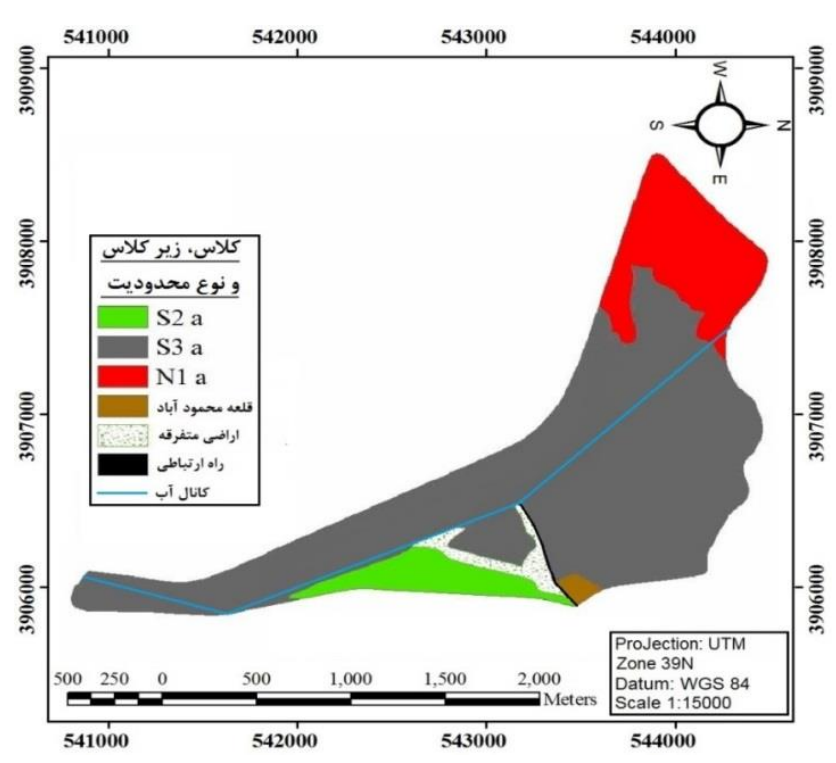

شكل 0- نقشه تناسب اراضى براى احداث باغ پـته 


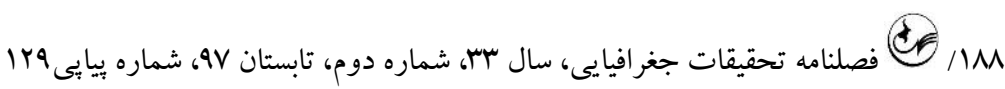
نتيجه گيرى

بهطور كلى خاك هاى منطقه موردمطالعه در رده خاكهاى تحول نيافته' و يا كم تحوليافته و در غالب سه سرى قنبر آباد ا، قنبر آباد r و قنبر آباد ب نام كذارى شدند. خاكهاى سرى قنبر آباد ا كه در قسمت جنوبى منطقه كسترشيافته است، كمى مشكل شورى دارند. خاكهاى سرى قنبر آباد Y كه در قسمت شرق منطقه قرار دارد، ازنظر شورى خاك، محدوديت بيشترى نسبت به سرى قنبر آباد ا دارند. خاك هاى سرى قنبر آباد م در قسمت شمالى منطقه، داراى بيشترين شدت محدوديت شورى، قليائيت و سيل كيرى هستند. با توجه به اينكه در اين تحقيق سطح مديريت متوسط در نظر كرفتهشه است، بنابراين، يس از مشخص شدن محل استقرار نهالها از روش جال كود يا كانال كود همراه با خاك باكيفيت مناسب (منابع قرضه) استفاده خواهد شد. از سوى ديكر، يس از استقرار سامانه آبيارى حبابساز با توجه به ايجاد يياز رطوبتى دائمى در ريزوسفر ريشههاى درخت، باعث مىشود تا شورى خاك هاى اطراف و بهخصوص نمكىهاى تجمع يافته در سطح خاكى به محيط ريشه منتقل نشود. بنابراين درجه تناسب اراضى براى كاشت يسته ارتقاء بيدا مى كند. با توجه به محدوديت شورى، قليائيت و سيل كيرى، استفاده از روش آبيارى حبابساز، سيلبند و منابع قرضه مىتواند منجر به بهبود درجات تناسب اراضى براى نوع بهرهورى يسته شود. لذا هزينه هاى عمرانى و فنى اوليه از طريق زير كشت بردن منطقه، مصرف آب كمتر و افزايش عملكرد در بلندمدت جبران خواهد شد. همانطور كه اين تحقيق نشان داد تغيير روش آبيارى از سنتى به مدرن: 1) سبب افزايش مساحت اراضى با درجه يا كلاس مرغوبتر شده و يا در يك كلاس ثابت، تعداد يا شدت محدوديتها كاهش ويداكرده است كه موجب افزايش در آمد زارعين

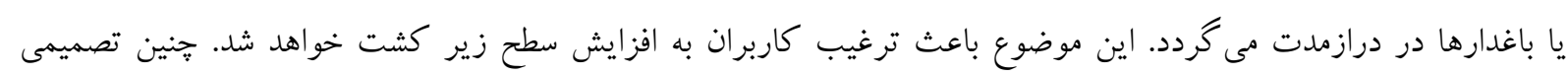
عملياتى نمىشود مخر با به كاركيرى و استخدام نيروى انسانى بومى و متخصص. r) سبب ايجاد و رونق صنايع بالادستى و يائيندستى آن خواهد شد، ازجمله؛ توليد و فروش تجهيزات آبيارى مدرن (سختافزارى و نرمافزارى) و خدمات يس پيس از فروش آنها (مانند نكهدارى و تعميرات). ץ) سبب صرفه جويى در حجم آب مصرفى و بهعبارتديخر افزايش راندمان آبيارى مىشود. بيكى و همكاران (عهسا) نيز اشاره دارند كه ميزان اشتغالآفرينى روشهاى نوين آبيارى (خاصه تحتفشار) نسبت به آبيارى سطحى (سنتى)، س/r برابر است. درنهايت مىتوان كفت نهتنها در اين منطقه بلكه در بسيارى از مناطق مشابه در كشور باكمى انتقال فن آورى و مطالعات زيربنايى كاربردى قادر به ايجاد اشتغال و در آمدزايى يايدار خواهيم بود.

سهم نويسندگان: كامران مروج (نويسنده اول)، يزوهشخر اصلى، نخارنده بحث (·و٪)، محمداميردلاور(نويسنده دوم)،

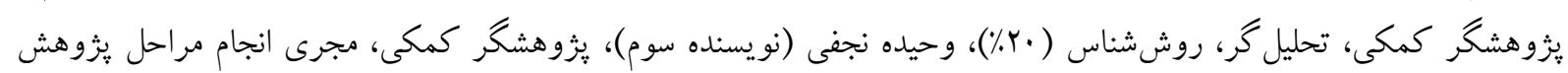

\section{منابع و مآخذ}

Ahmadi, A., \& Barzgari, F. (2012). Economic study of bubbler irrigation in pistachio gardens, case study: Herat district, Yazd province, Iran. Paper presented at the Fifth National Conference on Watershed Management and Water Resources Management, Kerman. (Persian)

Albaji, M., Landi, A., Nasab, S. B., \& Moravej, K. (2008). Land suitability evaluation for surface and drip irrigation in Shavoor Plain Iran. Journal of Applied Sciences, 8(4), 654-659. [DOI:10.3923/jas.2008.654.659]

Albaji, M., Nasab, S. B., Kashkoli, H. A., \& Naseri, A. (2010). Comparison of different irrigation methods based on the parametric evaluation approach in the plain west of Shush, Iran. Irrigation and Drainage, 59(5), 547-558. [DOI:10.1002/ird.520]

Alipour, A., Hosseini, J., \& Ghaffari, F. (2012). Determination of salinity resistance in pistachio pulp cultivars using controlled crosses. Plant Production Research, 19(3), 39-58. (Persian) 
Alsaqaf, A. M. A. (2015). Determination of friction head losses in trickle (bubbler) and sprinkler irrigation systems. (Ph.D), University of Khartoum, Morocco.

Anonymous. (2014). World reference base for soil resources. International soil classification system for naming soils and creating legends for soil maps. Rome: FAO.

Askari, B., Fahimi, R., Tavakoli Poor, H., \& Mokhtari, F. (2011). Evaluation of geometric properties of two Iranian pistachio varieties. Paper presented at the 20th National Congress of Food Science and Technology, Tehran. (Persian)

Beede, R. H., Brown, P. H., Kallsen, C., \& Weinbaum, S. A. (2005). Diagnosing and correcting nutrient deficiencies. Pistachio production ,manual (Forth ed.): University of California, Davis, USA.

Beyki, A., Pordel, I., Khashaei, S. A., \& Dasturati, M. (2017). Study of employment status in traditional irrigation systems and modern irrigation. Paper presented at the The First National Conference on New Opportunities for Agricultural Production and Employment in the East of the Country, Birjand. (Persian)

Bouyoucos, G. J. (1962). Hydrometer method improved for making particle size analyses of soils. Agronomy journal, 54(5), 464-465. [DOI:10.2134/agronj1962.00021962005400050028x]

Burt, R. (2004). Soil survey laboratory (methods manual). Soil Survey Investigations Report: No: 42. Version: 4.0. NRCS, USDA.

Darvishzadeh, A. (1991). Iran geology (First ed.). Tehran: Amir Kabir Press. (Persian)

Darwish, T., Atallah, T., El Moujabber, M., \& Khatib, N. (2005). Salinity evolution and crop response to secondary soil salinity in two agro-climatic zones in Lebanon. Agricultural water management, 78(1-2), 152-164.

Ebrahimi, H. (2006). Performance Evaluation of Pressure Irrigation Methods in Khorasan Province. Scientific Journal of Agricultural Sciences, 12(3), 577-589. (Persian)

Eduful, M., \& Shively, D. (2015). Perceptions of urban land use and degradation of water bodies in Kumasi, Ghana. Habitat International, 50, 206-213. [DOI:10.1016/j.habitatint.2015.08.034]

El-Gindy, A., Mahmoud, A., \& Mohamed, A. (2016). Influence of using different water quantities and irrigation systems on some forest trees growth parameters. Life Science Journal, 13(1), 72-82.

FAO. (1998). Soil Map of the World. Revised Legend. World Soil Resources Report, No: 60. Rome, Italy.

Farshad, A., Mohammadi, M., \& Masihabadi, M. H. (2015). Application of geomorphology, remote sensing and geographic information system in soil (First ed.). Tehran: Soil and Water Research Institute. (Persian)

Farshi, A. A., Shariati, M. R., Jarollahi, R., Ghaemi, M. R., Shahabifar, M., \& Tulaei, M. (1997). Estimation of water requirements for major agronomic and horticultural plants in Iran (Vol. 1). Karaj: Agricultural Education Publishing. (Persian)

Ghaemian, N., \& Najari, S. (2013). Evaluation of the suitability of pistachio salmon farming in the marginal lands of Orumieh lake in Miandoab, Iran. Paper presented at the First National Conference on the Impact of Lake Urmia on the Soil and Water Resources, Tabriz. (Persian)

Jafarzadeh, A. A., \& Abbasi, G. (2006). Qualitative land suitability evaluation for the growth of onion, potato, maize, and alfalfa on soils of the Khalat pushan research station. Biologia, 61(19), S349-S352. [DOI:10.2478/s11756-006-0187-5]

Jalalian, H. (2013). The analysis of the impacts of new irrigation systems on agriculture exploitation in Khodabandeh county. Space Economy and Rural Development, 1(2), 41-64. (Persian)

Khalifa, A. B., \& Ali, M. A. (2015). Water productivity, yield and quality of foster grapefruit irrigated by bubbler and surface irrigation under Khartoum State conditions. Gezira Journal of Agricultural Science, 13(1), 34-45.

Khidir, S. M. (1986). A statistical approach in the use of parametric systems applied to the FAO framework for land evaluation. (Ph.D), State University of Ghent, Belgium.

Mahajan, S., \& Tuteja, N. (2005). Cold, salinity and drought stresses: an overview. Archives of biochemistry and biophysics, 444(2), 139-158. [DOI:10.1016/j.abb.2005.10.018]

Mansour, H. A., Abdallah, E. F., Gaballah, M. S., \& Gyuricza, C. (2015). Impact of bubbler discharge and irrigation water quantity on 1-hydraulic performance evaluation and maize biomass yield. International Journal of Geomate, 9(2), 1538-1544. [DOI:10.21660/2015.18.20856]

Moravej, K. (2017). Classification and land suitability for the development of disadvantaged regions in the framework of resistance economics (case Study: Rigan, southeast of Kerman province). Geography and Development, 15(48), 133-151. (Persian)

Nelson, R. E. (1982). Carbonate and gypsum. Methods of doil analysis. part II. (A. L. Page Ed.). Madison: American Society of Agronomy.

Ojidi, A., Esfandiarropour, B. I., \& Hosseinifard, S. J. (2011). Statistical zoning of land suitability for pistachio in Hormozabad, Rafsanjan. (Master's Thesis), University of valiasr, Rafsanjan. (Persian) 


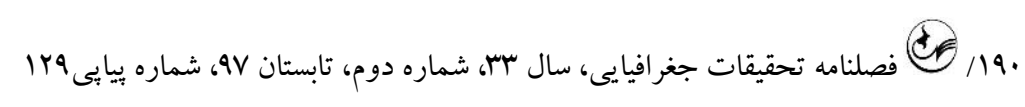

Onder, S., Caliskan, M. E., Onder, D., \& Caliskan, S. (2005). Different irrigation methods and water stress effects on potato yield and yield components. Agricultural Water Management, 73(1), 73-86. [DOI:10.1016/j.agwat.2004.09.023]

Phocaides, A. (2007). Handbook on pressurized irrigation techniques (Second ed.): Food \& Agriculture Org.

Rabia, A. H., Figueredo, H., Huong, T., Lopez, B., Solomon, H., \& Alessandro, V. (2013). Land suitability analysis for policy making assistance: a GIS based land suitability comparison between surface and drip irrigation systems. International Journal of Environmental Science and Development, 4(1), 1-6. [DOI:10.7763/IJESD.2013.V4.292]

Rhoades, J. D., Sparks, D. L., Page, A. L., Helmke, P. A., Loeppert, R. H., Soltanpour, P. N., \& Sumner, M. E. (1996). Salinity: Electrical conductivity and yotal dissolved solids. Methods of soil analysis. Part 3Chemical methods: Soil Science Society of America, Madison.

Salem, J. (2018). Investigation of factors affecting the non-use of pressure irrigation methods by pistachio exporters of Yazd province. Journal of Water Research in Agriculture, 31(4), 585-594. (Persian)

Seyyedjalali, A. R., Sarmandian, F., \& Shorafa, M. (2014). Comparison of land improvement and land index indicators in the parametric method of land suitability evaluation. Soil Researches Journal, 28(1), 3545. (Persian)

SoilResearchInstitute. (1989). Land use classification guide for irrigation (Journal No. 205). Tehran: Agricultural Research and Education Organization, Ministry of Agriculture. (Persian)

Soil Survey Staff. (2014). Keys to Soil Taxonomy. Washington D.C: United States Department of Agriculture Natural Resources Conservation Service.

Soothar, R. K., Chandio, A. S., Mirjat, M. S., \& Ahmed, M. (2015). Comparison of bubbler and basin irrigation methods in a bivarietal mangifera indica orchard in Pakistan. Science International, 27(2), 1229-1236.

Sys, C. E., Van Ranst, E., \& Debaveye, J. (1991). Land evaluation, part I: Methods in land evaluation: International Training Center for Post Graduate Soil Scientists, Ghent University, Ghent, Belgium.

Traylor, J. P., \& Zlotnik, V. A. (2016). Analytical modeling of irrigation and land use effects on streamflow in semi-arid conditions. Journal of Hydrology, 533, 591-602.

Van Wambeke, A. R. (2000). The newhall simulation model for estimating soil moisture and temperature regimes. Department of Crop and Soil Sciences. Cornell University, Ithaca, NY. USA.

Waller, P., \& Yitayew, M. (2016). Low-head gravity bubbler irrigation system. Irrigation and Drainage Engineering (pp. 387-411). Berlin: Springer. [DOI:10.1007/978-3-319-05699-9_22]

Zaynaldin, A., Masiahabadi, M. H., \& Esfandiari, M. (2013). An investigation of genesis, classification and physico-chemical soil properties of cultivation pistachio Sirjan plain, Kerman province. Quarterly Journal of Modern Knowledge of Sustainable Agriculture, 10(2), 31-41. (Persian) 